\title{
Targeted Delivery of Erythropoietin Hybridized with Magnetic Nanocarriers for the Treatment of Central Nervous System Injury: A Literature Review
}

This article was published in the following Dove Press journal:

International Journal of Nanomedicine

\section{Chang Ho Hwang (1D}

Department of Physical and Rehabilitation Medicine, Chungnam National University Sejong Hospital, Chungnam National University College of Medicine, Sejong, Republic of Korea
Correspondence: Chang Ho Hwang Department of Physical and Rehabilitation Medicine, Chungnam National University Sejong Hospital, Chungnam National University, College of Medicine, 30099,

20, Bodeum 7-Ro, Sejong, Republic of Korea

$\mathrm{Tel}+82-44-995-4715$

Fax +82-44-995-246I

Email chhwang1220@cnu.ac.kr

\begin{abstract}
Although the incidence of central nervous system injuries has continued to rise, no promising treatments have been elucidated. Erythropoietin plays an important role in neuroprotection and neuroregeneration as well as in erythropoiesis. Moreover, the current worldwide use of erythropoietin in the treatment of hematologic diseases allows for its ready application in patients with central nervous system injuries. However, erythropoietin has a very short therapeutic time window (within 6-8 hours) after injury, and it has both hematopoietic and nonhematopoietic receptors, which exhibit heterogenic and phylogenetic differences. These differences lead to limited amounts of erythropoietin binding to in situ erythropoietin receptors. The lack of high-quality evidence for clinical use and the promising results of in vitro/in vivo models necessitate fast targeted delivery agents such as nanocarriers. Among current nanocarriers, noncovalent polymer-entrapping or polymer-adsorbing erythropoietin obtained by nanospray drying may be the most promising. With the incorporation of magnetic nanocarriers into an erythropoietin polymer, spatiotemporal external magnetic navigation is another area of great interest for targeted delivery within the therapeutic time window. Intravenous administration is the most readily used route. Manufactured erythropoietin nanocarriers should be clearly characterized using bioengineering analyses of the in vivo size distribution and the quality of entrapment or adsorption. Further preclinical trials are required to increase the therapeutic bioavailability (in vivo biological identity alteration, passage through the lung capillaries or the blood brain barrier, and timely degradation followed by removal of the nanocarriers from the body) and decrease the adverse effects (hematological complications, neurotoxicity, and cytotoxicity), especially of the nanocarrier.
\end{abstract}

Keywords: erythropoietin, nanoparticles, polymers, magnetics, central nervous system, regeneration

\section{Introduction}

\section{Erythropoietin Biology and Mechanism of Action} Structure

The chemical formula of erythropoietin (EPO) is $\mathrm{C}_{815} \mathrm{H}_{1317} \mathrm{~N}_{233} \mathrm{O}_{241} \mathrm{~S}_{5}$. ${ }^{1}$ In addition to the well-known hematopoietic function, extrahematopoietic actions of EPO have been observed in various organs, including neuroprotection in the brain and spinal cord, cardioprotection, renoprotection, cytoprotection in the lung and gastrointestinal tract, 
retinal angiogenesis, and improved male reproductive function and skeletal muscle bioenergetics. ${ }^{2,3}$

\section{Phylogenetic Differences in Erythropoietin Genes}

While in vitro/in vivo animal experiments on EPO, such as murine EPO, have been widely utilized, genetic differences in EPO can occur among vertebrates, and genetic homology should be compared between human and murine species prior to experiments. The genetic homology of mouse EPO with recombinant human EPO (rhEPO) is no more than $80 \%$ based on nucleotide sequence analysis. ${ }^{4}$ Compared to rhEPO, the genetic homology of rat EPO is $79 \% .^{5}$ Additionally, that of monkeys is 92-94\%. ${ }^{6}$ The diverse conservation (79-94\%) of EPO in other species relative to rhEPO may be a potentially significant difference and may explain why there has been a history of difficulties reproducing the results of animal studies in humans. Therefore, the selection of either EPO of other species or rhEPO should be made in accordance with the genetics of the experimental species.

\section{Neuroprotective Actions of Erythropoietin}

Central nervous system (CNS) injuries, such as spinal cord and brain injuries, induce severe neurological complications in the majority of patients, and medical costs related to CNS injury have continued to increase for both individuals and nations over time. Among the numerous therapeutic tools under development for CNS injuries, ${ }^{7} \mathrm{EPO}$ has been extensively evaluated in brain and spinal cord injury models both in vitro and in vivo. ${ }^{8-12}$ In the presence of EPO, neuroprotection or regeneration has been reported since the early 2000 s. ${ }^{7,10,11,13}$ However, persistent challenges have hindered the successful application of EPO in the treatment of CNS injuries despite the promising results reported at the preclinical level; on nucleotide sequencebased phylogenetic analysis, phylogenetically conserved vertebrate EPO receptors remain in the human body. ${ }^{14-16}$ Regarding neuroprotection, heterogeneous subcomplexes have been reported in nonhematopoietic EPO receptors. ${ }^{17,18}$ Furthermore, EPO has a very short therapeutic time window (within 6-8 hours) after injury. ${ }^{19-21}$ As a result, limited amounts of EPO are expected to arrive at the targeted area and to bind in situ EPO receptors on time for neuroprotection.

\section{Neuromolecular Cascade}

Following primary insults (ischemia, anoxia, hemorrhage, contusion, concussion, compression, acceleration, deceleration, etc.) in CNS injuries, secondary neuronal insulting cascades are always triggered. ${ }^{22}$ For example, subsequent reactive astrogliosis upregulates two kinds of intermediate filaments (glial fibrillary acidic protein [GFAP] and vimentin) as well as neuroinhibitory molecules (chondroitin sulfate proteoglycans $[\mathrm{CSPG}])^{23}$ and promotes the secretion of proinflammatory cytokines (tumor necrosis factor-alpha $[\mathrm{TNF}-\alpha]$, transforming growth factor-beta [TGF- $\beta]$, interleukins-1, and interleukins-6). ${ }^{24}$ Simultaneously, activated Rho-associated protein kinase (ROCK) signaling increases neuronal cell apoptosis, ${ }^{25}$ and the upregulated ephrinA4 pathway prevents axonal regeneration. ${ }^{26}$

The following neuromolecular cascades are involved in the regeneration of EPO for neuroprotection against secondary neuronal insults: Janus kinase (JAK2) expression via signal transducer and activator of transcription (STAT), phosphatidylinositol 3-kinase/protein kinase $\mathrm{B}$ (PI3K/AKT), or Ras-mitogen-activated protein kinase (MAPK) signaling following EPO receptor activation. These cascades result in altered DNA translation within the nucleus for cell survival pathway- or apoptosis pathway-related protein synthesis (Figure 1);,19 ROCK expression via RhoA signaling and ephrin expression via Eph/ephrin signaling for neuroinhibitory cytoskeletal molecule (GFAP, CSPG, vimentin) production, ${ }^{23}$ resulting in altered cell migration by actin instability or actin monomer loss; ${ }^{27,28}$ and TGF- $\beta$ expression via Smad and Daxx signaling for proinflammatory cytokine release; for example, TGF- $\beta 1$ induces an acute inflammatory response and glial scar formation, and TGF- $\beta 2$ maintains the glial scar. $^{2,19,29-31}$

\section{Current Modes of Erythropoietin Delivery in Central Nervous System}

EPO has been attempted to be administered via the following routes: ${ }^{28}$ intramuscular injection, intestinal implantation using patches, ${ }^{32}$ implantation under the stomach using chambers, ${ }^{33}$ intraperitoneal implantation using hollow fibers, ${ }^{34}$ intrathecal implantation using hydrogels, ${ }^{35}$ and subcutaneous implantation using microspheres (Table 1). ${ }^{36}$ However, all of these methods are currently being investigated for systemic routes in pioneering trials and thus require further evaluation prior to discussion about whether these routes have any effect on CNS penetration of EPO. 


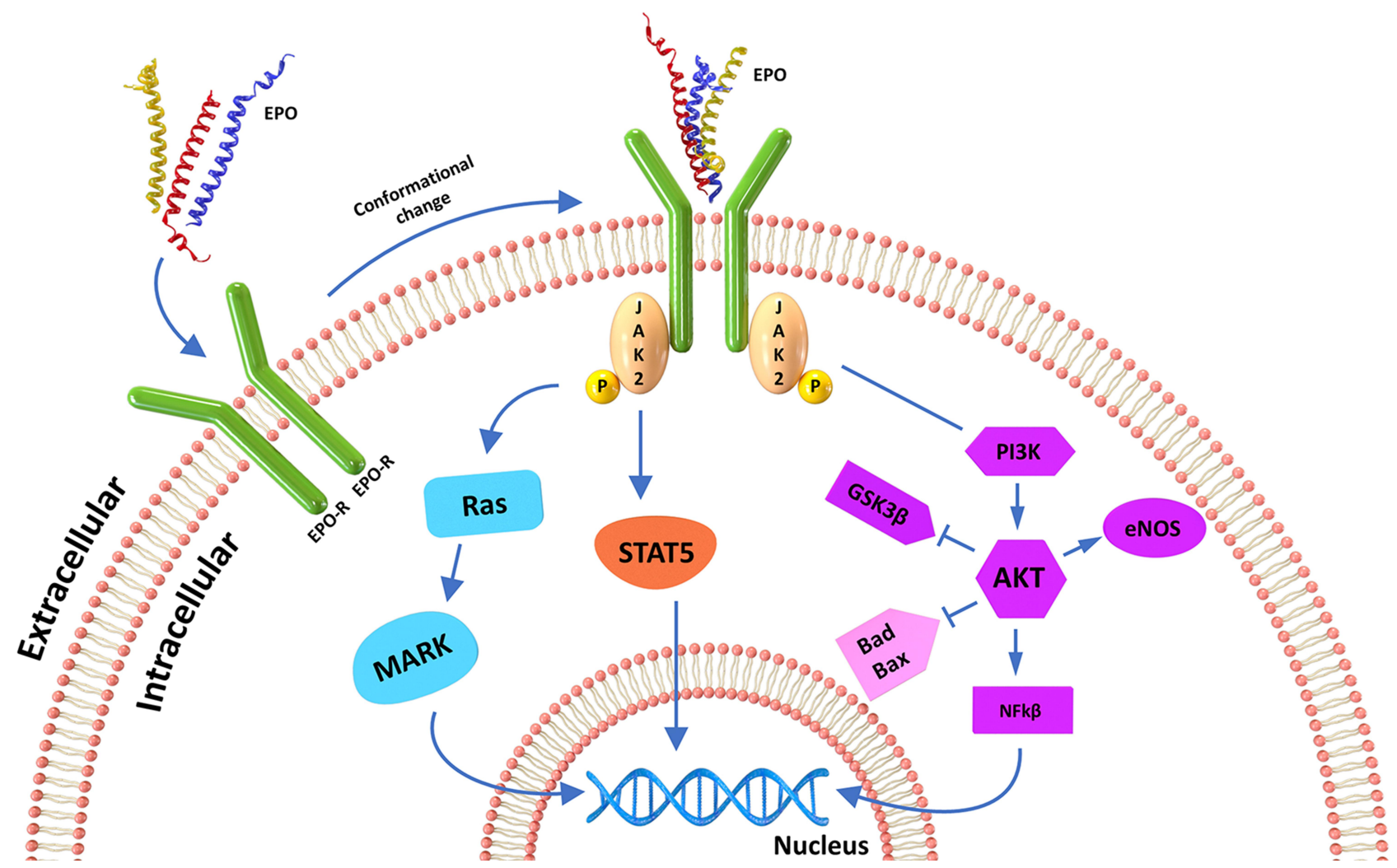

Figure I Simplified diagram showing the signaling cascades mediating the nonhematopoietic neuroprotective effects of erythropoietin. Modified with permission from Murua A, Orive G, Hernandez RM, Pedraz JL. Emerging technologies in the delivery of erythropoietin for therapeutics. Medicinal research reviews. 20 I I;3 I(2):284-309. Copyright 201I, John Wiley and Sons. ${ }^{2}$

Therefore, the author starts by discussing two routes of administration that have been widely studied.

\section{Intranasal Administration}

In contrast to the aforementioned routes, the nasal administration of EPO could reach the brain by the olfactory pathways, as previously shown in humans for huge proteins, such as the neurotrophic factors. After intranasal spraying, therapeutics can bypass the blood-brain barrier (BBB) with the help of intracellular axonal, paracellular or trigeminal pathways from within minutes to a few hours. $^{37,38}$ A single bolus intranasal administration (10 $\mu \mathrm{g} / 10 \mu \mathrm{L})$ of rhEPO showed 2- to 5 -times greater brain uptake than intraperitoneal injection $(100 \mu \mathrm{g} / 100 \mu \mathrm{L}) 30$ minutes to 12 hours later in mice. ${ }^{39}$ Moreover, the intranasal provision of recombinant nonhematopoietic EPO (0.25-0.5 mg/every 8 hours over 4 days) caused minor adverse effects, such as nasopharyngeal itching or headache, in a Phase I open-label trial of safety in 25 healthy volunteers in $2017 .^{40}$ In succession, 5 open-label trials of the safety and efficacy of the same EPO have been conducted in stroke, Parkinson's disease, dementia and neurodegenerative disease patients in Cuba (the Cuban Registry of Clinical Trials: https://rpcec.sld.cu/en/home) ${ }^{37}$ However, these 5 trials have been either pending or recruiting since 2014. Moreover, the only published report on adverse effects was based only on clinical examination and blood tests 5 and 10 days after the end of treatment. ${ }^{40}$ Additionally, most intranasal EPO administration trials have been sponsored by one biopharmaceutical company (CIDEM).

The transnasal delivery of pure proteins is known to result in very low bioavailability ${ }^{41}$ for instance, the intranasal administration of pure growth hormone showed $1-3 \%$ of the bioavailability achieved by subcutaneous injection. ${ }^{39,42}$ Similarly, in the majority of animal experiments, intranasal EPO administration requires a much higher dose of EPO (575-2490 IU/mL) for sufficient transnasal delivery to the $\mathrm{CNS}^{43-45}$ than intraperitoneal injection $(10 \mathrm{IU} / \mathrm{mL}) .{ }^{46-49}$ To enhance absorption of therapeutics, various kinds of lipoamino acid colloids have been tested; for example, mixing sodium tauro-24,25dihydrofusidate with growth hormone solution could improve the bioavailability by 11 -fold in rabbits and 
Table I Summary of Administration Routes, Advantages, and Disadvantages of Erythropoietin

\begin{tabular}{|c|c|c|c|c|}
\hline Route of Administration & Author & $\begin{array}{l}\text { Published } \\
\text { Year }\end{array}$ & $\begin{array}{l}\text { In vivo } \\
\text { Model }\end{array}$ & Remarks \\
\hline \multicolumn{5}{|l|}{ Implantation } \\
\hline Implantation using patches ${ }^{32}$ & $\begin{array}{l}\text { Venkatesan, N. Uchino, } \\
\text { K. Amagase, K. Ito, Y. Shibata, N. } \\
\text { Takada, K. }\end{array}$ & 2006 & Rats & $\begin{array}{l}\text { Gastro-intestinal patches } \\
\text { Optimal absorption site of jejunum } \\
\text { Optimal absorption dose of } 100 \mathrm{lU} / \mathrm{kg}\end{array}$ \\
\hline $\begin{array}{l}\text { Implantation } \\
\text { under the stomach using } \\
\text { chambers }^{33}\end{array}$ & $\begin{array}{l}\text { Lejnieks, D. V. Ramesh, N. Lau, } \\
\text { S. Osborne, W. R. }\end{array}$ & 1998 & Rats & $\begin{array}{l}\text { Ring vascularized under the serosa } \\
\text { Alteration of erythropoietin mRNA } \\
\text { transcription }\end{array}$ \\
\hline $\begin{array}{l}\text { Intraperitoneal implantation } \\
\text { using hollow fibers }{ }^{34}\end{array}$ & $\begin{array}{l}\text { Schwenter, F. Schneider, } \\
\text { B. L. Pralong, W. F. Deglon, } \\
\text { N. Aebischer, P. }\end{array}$ & 2004 & Mice & $\begin{array}{l}\text { Xenogenic cells for erythropoietin gene } \\
\text { therapy I } 70 \text { IU erythropoietin secretion a day }\end{array}$ \\
\hline $\begin{array}{l}\text { Intrathecal implantation using } \\
\text { hydrogels }\end{array}$ & $\begin{array}{l}\text { Kang, C. E. Poon, P. C. Tator, } \\
\text { C. H. Shoichet, M. S. }\end{array}$ & 2009 & Rats & $\begin{array}{l}\text { Hydrogel of methylcellulose and } \\
\text { hyaluronate } 80 \% \text { bioavailability }\end{array}$ \\
\hline $\begin{array}{l}\text { Subcutaneous implantation } \\
\text { using microspheres }\end{array}$ & $\begin{array}{l}\text { Geng, Y. Yuan, W. Wu, F. Chen, } \\
\text { J. He, M. Jin, T. }\end{array}$ & 2008 & Mice & $\begin{array}{l}\text { Microencapsulated erythropoietin into poly } \\
\text { lactic-co-glycolic acid microspheres }\end{array}$ \\
\hline \multirow[t]{5}{*}{ Intranasal spraying } & Garcia-Rodriguez, J. C. Sosa-Teste, I. & 2009 & Humans & Easy bypass of the blood-brain barrier ${ }^{37}$ \\
\hline & Chauhan, M. B. Chauhan, N. B. & 2015 & Mice & $\begin{array}{l}\text { Greater brain uptake than intraperitoneal } \\
\text { injection }^{39}\end{array}$ \\
\hline & Santos-Morales, et al ( 26 persons) & 2017 & Humans & $\begin{array}{l}\text { Minor adverse systemic effects } \\
\text { Just clinical examination and blood tests } 5 \text { and } \\
10 \text { days after spraying Only one } \\
\text { biopharmaceutical company sponsor }{ }^{40}\end{array}$ \\
\hline & $\begin{array}{l}\text { Ma, R. Xiong, N. Huang, C. Tang, } \\
\text { Q. Hu, B. Xiang, J. Li, G. }\end{array}$ & 2009 & Rats & Very low bioavailability ${ }^{49}$ \\
\hline & $\begin{array}{l}\text { Bijani, C. Arnarez, C. Brasselet, } \\
\text { S. Degert, C. Broussaud, } \\
\text { O. Elezgaray, J. Dufourc, E. J. }\end{array}$ & 2012 & Humans & Necessity of absorption enhancers ${ }^{41}$ \\
\hline \multirow[t]{6}{*}{ Intravenous injection } & $\begin{array}{l}\text { Vitellaro-Zuccarello, L. Mazzetti, } \\
\text { S. Madaschi, L. Bosisio, P. Gorio, } \\
\text { A. De Biasi, S. }\end{array}$ & 2007 & Rats & $\begin{array}{l}\text { The most popular administration route in } \\
\text { neuroprotective studies } \\
54\end{array}$ \\
\hline & Fisher, J. W. & 2003 & $\mathrm{~N} / \mathrm{A}$ & $\begin{array}{l}\text { Application readiness to patients with CNS } \\
\text { injuries }^{55}\end{array}$ \\
\hline & Ocampo Daza, D. Larhammar, D. & 2018 & Vertebrates & $\begin{array}{l}\text { Significant phylogenetic differences and } \\
\text { heterogeneity }\end{array}$ \\
\hline & $\begin{array}{l}\text { Hong, H. N. Shim, J. H. Won, } \\
\text { Y. J. Yoo, J. Y. Hwang, C. H. }\end{array}$ & 2018 & Rats & Very short therapeutic time window ${ }^{19}$ \\
\hline & $\begin{array}{l}\text { Lippi, G. Franchini, M. Favaloro, } \\
\text { E. J. }\end{array}$ & 2010 & $\mathrm{~N} / \mathrm{A}$ & Various hematopoietic complications ${ }^{59}$ \\
\hline & Jelkmann, W. & 2004 & N/A & Short half-life ${ }^{140}$ \\
\hline
\end{tabular}


rats. ${ }^{50}$ Similarly, mixing of lauroyl proline with rhEPO increased the relative permeability of pure rhEPO through nasal cells in vitro by 3.8 - to 12.1 -fold. ${ }^{41}$ However, these kinds of colloids can damage nasal cells; sodium tauro24,25-dihydrofusidate irreversibly stops the ciliary movement of nasal epithelial cells in a few minutes. ${ }^{51,52}$ In addition to causing cell damage, it can denature the protein structure; adding lauroyl proline could cause a decrease in the $\alpha$-helix content of EPO (39\%) and increase the deconvolution of EPO $(76 \%)$ in vitro. ${ }^{41}$

Taking into consideration the aforementioned problems, whether intranasal administration is the optimal route to the CNS remains to be studied.

\section{Intravenous Administration}

The intravenous injection of EPO is the most popular administration route in humans, and EPO administered in this manner has been reported to exert neuroprotective and neuroregenerative effects in numerous mouse and rat CNS injury models. ${ }^{10,53,54}$ The worldwide use of EPO in the treatment of hematological diseases guarantees that it does not need further approval as a new drug; therefore, it can be more readily available to patients with CNS injuries than other drugs currently under development. ${ }^{55}$ However, both nonhematopoietic and hematopoietic receptors coexist in the human body, with significant phylogenetic differences and heterogeneity. ${ }^{14-18}$ When EPO is administered intravenously, competition for simultaneous binding to heterogeneous complexes of nonhematopoietic EPO receptors and hematopoietic EPO receptors, both of which are phylogenetically diverse, is expected to begin quickly. ${ }^{56}$ Only limited amounts of intravenously injected EPO are anticipated to reach a target area, and escape of EPO from binding non-in situ EPO receptors is required for efficacy. ${ }^{57,58}$

The therapeutic time window of EPO has been reported to be very short (within 6-8 hours) in CNS injury models in vitro and in vivo. ${ }^{19-21}$ However, transferring patients to a hospital within that amount of time following injury is very difficult in unpredictable clinical situations. Therefore, the small amount of high-quality evidence supporting the efficacy of its clinical use and the promising in vitro/vivo model results demand the development of novel delivery methods.

Because of its hematopoietic action, hematopoietic complications have been reported, including thrombosis, upregulated viscosity, and teratogenicity. ${ }^{59}$ Even though the intravenous administration of EPO is already available to patients, methods to avoid these adverse events should be sought prior to clinical application. Potential solutions to this complex problem are reviewed in the discussion section.

\section{Innovative Methods for Erythropoietin Delivery in Central Nervous System Injury Targeted Delivery}

To improve the clinical feasibility of EPO by combating its short therapeutic time window, ensuring the quick targeted delivery of EPO to an injury site is critical. Carriers for the targeted delivery of therapeutic agents have been extensively evaluated since the late 1970s. ${ }^{60}$ However, few reports have described the targeted delivery of EPO in the context of CNS injury; in fact, indirect methods, such as epicortical implantation following craniotomy and delivery ${ }^{61}$ and crossing the BBB with the aid of focused ultrasound sonication using microbubbles, have been described. ${ }^{20}$ As a direct method, the use of nanocarriers has gained popularity in general medical fields since the report by Patel ${ }^{5,6}$ et al in 2006. ${ }^{60}$ However, prior EPO nanocarrier trials did not examine targeted delivery but rather examined only the additive/synergistic effects of EPO and nanocarriers. ${ }^{62-65}$

\section{Nanocarriers}

Nanoparticles are defined as those of any shape measuring from $1 \times 10^{-9} \mathrm{~m}$ to $1 \times 10^{-7} \mathrm{~m}$ (Table 2). Although $100 \mathrm{~nm}$ is the limit of differentiation from macromolecules, other characteristics, such as filtration capability, dispersion, and transparency, should be considered to allow the nanoparticle classification to extended to approximately $500 \mathrm{~nm}$. In addition, fibers and tubes under $100 \mathrm{~nm}$ in 2 dimensions can be included in this classification. ${ }^{66}$ As biotechnologies for targeted therapeutic delivery have advanced, the word "nanoparticle" is often interchangeable with the words "nanocarrier", "smart nanoparticle", and "nanobot". In my opinion, nanocarriers are preferred for targeted EPO delivery. Among them, magnetic nanocarriers refer to any nanoparticles exerting magnetic properties, ${ }^{67}$ and this specific characteristic is reviewed in the next section in detail. As drug carriers, their biocapability of staying in the blood or serum for prolonged amounts of time and their complex surface, which guarantees longer EPO exposure and a high contact ratio with EPO receptors, can be useful to improve the efficacy of targeted EPO delivery. ${ }^{68}$ Moreover, smaller 
Table 2 Summary of Targeted Nanocarrier Drug Delivery Studies

\begin{tabular}{|c|c|c|c|c|c|}
\hline \multirow{2}{*}{$\begin{array}{l}\text { Crosslinking } \\
\text { Covalent }\end{array}$} & \multirow{2}{*}{$\begin{array}{l}\text { Carrier } \\
\text { lonotropic gelation }\end{array}$} & \multirow{2}{*}{$\begin{array}{l}\text { Drug } \\
\begin{array}{l}\text { Double- } \\
\text { stranded siRNA }\end{array}\end{array}$} & \multicolumn{2}{|l|}{ Polymer } & \multirow{2}{*}{$\begin{array}{l}\text { Remarks } \\
\text { Significant drug loss during preparation } \\
\text { Poor stability in response to biological } \\
\text { changes } 98 \% \text { entrapment efficiency }{ }^{73}\end{array}$} \\
\hline & & & Natural & Dextran sulphate & \\
\hline & Polymer conjugates & Doxorubicin & Synthetic & $\begin{array}{l}\mathrm{N} \text {-(2-hydroxypropyl) } \\
\text { methacrylamide }\end{array}$ & $\begin{array}{l}\text { Enhanced permeability and retention effect, } \\
\text { but unstableness under inflammatory } \\
\text { conditions }{ }^{87} \text { No biodegradability of } \\
\mathrm{N} \text {-(2-hydroxypropyl) methacrylamide } \\
\text { backbone }{ }^{88}\end{array}$ \\
\hline \multirow[t]{13}{*}{ Noncovalent } & $\mathrm{N} / \mathrm{A}$ & $\mathrm{N} / \mathrm{A}$ & Synthetic & Polyethylene glycol & $\begin{array}{l}\text { The most commonly used synthetic } \\
\text { polymers for medical purposes }\end{array}$ \\
\hline & $\mathrm{N} / \mathrm{A}$ & $N / A$ & Synthetic & $\begin{array}{l}\text { Poly-L-lysine, poly } \varepsilon- \\
\text { caprolactone, poly } \\
\text { L-lactide, } \\
\text { polyethylenimine, and } \\
\text { polyacrylic acid }\end{array}$ & Alternatives to polyethylene glycol ${ }^{74}$ \\
\hline & \multirow[t]{2}{*}{$\begin{array}{l}\text { Nanocapsule } \\
\left(\mathrm{Fe}_{3} \mathrm{O}_{4}\right)\end{array}$} & $\begin{array}{l}\text { Erythropoietin } \\
\text { receptor cDNA }\end{array}$ & Synthetic & Poly-lactic glycolic acid & $\begin{array}{l}\text { Upregulated pulmonary erythropoietin } \\
\text { receptor expression }\end{array}$ \\
\hline & & Cisplatin & Natural & $\begin{array}{l}\text { Dextran/hyaluronic acid } \\
\text { hybrid }\end{array}$ & Dose-dependent apoptosis ${ }^{77}$ \\
\hline & Nanocapsule & Erythropoietin & Synthetic & Poly-lactic glycolic acid & $\begin{array}{l}\text { Penetration of the blood brain barrier } \\
\text { Reduced infarcted volume }{ }^{67}\end{array}$ \\
\hline & $\begin{array}{l}\text { Nanosphere } \\
\left(\mathrm{Fe}_{3} \mathrm{O}_{4}\right)\end{array}$ & Rapamycin & Natural & Carboxymethyl chitosan & Enhanced cellular uptake ${ }^{76}$ \\
\hline & Nanofilm & $\mathrm{N} / \mathrm{A}$ & Natural & Sodium alginate & Improved thermal stability ${ }^{75}$ \\
\hline & $\begin{array}{l}\text { Core- } \\
\text { shell-matrix }\left(\mathrm{Fe}_{3} \mathrm{O}_{4}\right)\end{array}$ & Mitoxantrone & Allogeneic & Fatty acid/albumin hybrids & Improved biocompatibility ${ }^{78}$ \\
\hline & \multirow[t]{2}{*}{ Liposome } & \multirow[t]{2}{*}{ Glucocorticoids } & Natural & Phosphatidylcholine & $\begin{array}{l}\text { Higher potency and long lasting, but slow } \\
\text { release }^{81} \text { Neuroprotection in Parkinson's } \\
\text { disease rat model }{ }^{82}\end{array}$ \\
\hline & & & Synthetic & $\begin{array}{l}\text { Polyethylene glycol-poly } \varepsilon- \\
\text { caprolactone }\end{array}$ & $\begin{array}{l}\text { Serious activation of the complement } \\
\text { system }^{86}\end{array}$ \\
\hline & \multirow[t]{3}{*}{ Micelles } & Doxorubicin & Natural & Palmitic acid & $\begin{array}{l}\text { Enhance drug loading, but modest } \\
\text { activation of the complement system }\end{array}$ \\
\hline & & $\mathrm{N} / \mathrm{A}$ & $\mathrm{N} / \mathrm{A}$ & $N / A$ & $\begin{array}{l}\text { Improved target specificity using } \\
\text { hydrophilic corona }^{85}\end{array}$ \\
\hline & & Dexamethasone & Synthetic & $\begin{array}{l}\text { Polyethylene glycol-poly } \varepsilon- \\
\text { caprolactone, }\end{array}$ & $\begin{array}{l}\text { Improved water solubility in spinal cord } \\
\text { injury rat model }{ }^{89}\end{array}$ \\
\hline
\end{tabular}

than other biologic structures (proteins: $<100 \mathrm{~nm}$; viruses: $<450 \mathrm{~nm}$; cells: $<100 \mathrm{~nm}$ ), their size can be another advantage, leading to fewer dimensional obstacles in regards to their delivery in physiologic conditions in cases for targeted delivery using their biologic fundamentals (for example, magnetic property) as a navigational power. ${ }^{69}$ The enhanced efficacy of targeted drug delivery has been reported in the context of combining magnetic field-sensitive magnetic nanocarriers with drugs. $^{67}$ 
Among the currently available nanocarriers, liposomes, micelles, conjugates, nanospheres and nanocapsules are commonly utilized, and the last two involve entrapment or adsorption on the surface. Noncovalent and covalent crosslinking have been used to manufacture nanocarriers (Figure 2). ${ }^{70-72}$ For covalent nanocarrier manufacturing, polymers are incorporated into therapeutic materials using ionotropic gelation or covalent crosslinking. However, both of these methods have pitfalls, such as significant drug loss during preparation or poor stability in response to biological changes (eg, ionic strength and $\mathrm{pH}$ ). ${ }^{73}$ For the manufacture of noncovalent nanocarriers, polyethylene glycol (PEG) polymers are the most commonly used synthetic polymers for medical purposes,$^{70}$ but poly-lactic glycolic acid (PLGA), poly-L-lysine (PK), poly $\varepsilon$ caprolactone (PCL), poly L-lactide, polyethylenimine and polyacrylic acid can be used as alternatives to PEG. ${ }^{65,67,74}$ As a natural carrier, a biodegradable nontoxic polymer, such as sodium alginate $(\alpha-\mathrm{L}$-guluronic acid units and $(1,4)$-linked $\beta$-D-mannuronic acid units) ${ }^{75}$ carboxymethyl chitosan $^{76}$ or a dextran/hyaluronic acid hybrid ${ }^{77}$ can also be used. In the form of allogeneic carriers, fatty acid/ albumin hybrids (nanocarriers coated by lauric acid and then shielded by albumin) could potentially be used. ${ }^{78}$

A liposome is a spheroid consisting of a phospholipid bilayer allowing the containment of both lipophilic and hydrophilic drugs in their luminal space. ${ }^{79}$ To improve their characteristics, such as half-life and stability, the surface can be modified using noncovalent polymer preparations. ${ }^{80}$ As another advantage, liposomes have the capability to constantly release the contained drugs over a very long time. ${ }^{81}$ Nevertheless, this kind of slow release is not appropriate for EPO nanocarriers in the case of CNS injury due to the short therapeutic time window of EPO. Therefore, these nanocarriers have been applied mostly in cancer and rheumatoid arthritis models, and only two trials have been conducted with stroke and Parkinson's disease models. ${ }^{82,83}$ Moreover, this approach can trigger serious activation of the complement system, resulting in coagulopathies such as thrombosis or bleeding tendencies.

Micelles are classically made by the self-assembly of amphiphilic supramolecular copolymers in aqueous solution;

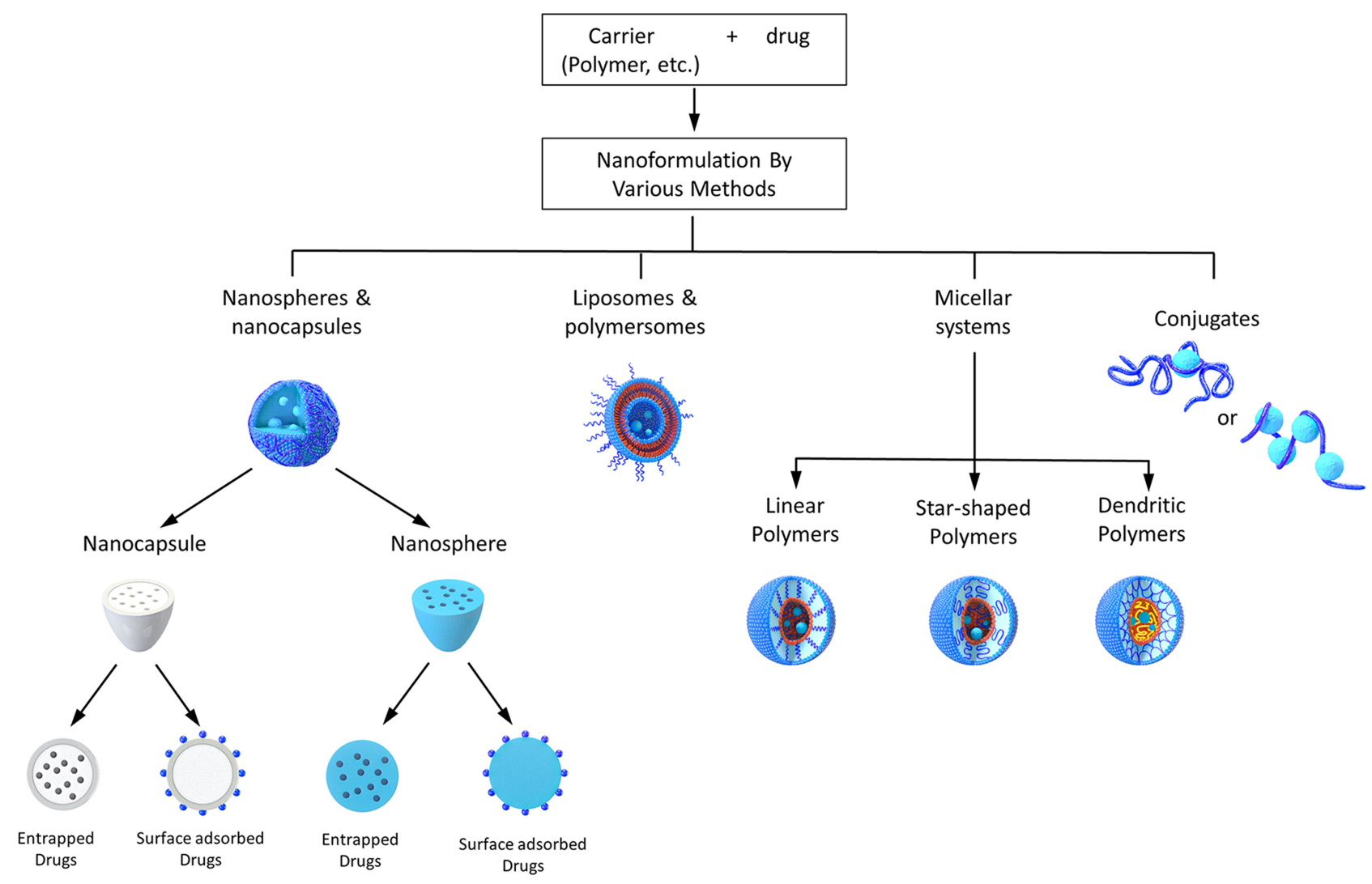

Figure 2 Types of nanocarriers for targeted drug delivery Modified with permission from Knop K, Hoogenboom R, Fischer D, Schubert US. Poly(ethylene glycol) in drug delivery: pros and cons as well as potential alternatives. Angewandte Chemie (International ed in English). 2010;49(36):6288-6308. Copyright 20I0, John Wiley and Sons. ${ }^{70}$ Modified with permission from Kumari A, Yadav SK, Yadav SC. Biodegradable polymeric nanoparticles based drug delivery systems. Colloids and surfaces B, Biointerfaces. 2010;75(I):I-18. Copyright 2010, Elsevier. ${ }^{72}$ 
linear polymer, star-shaped polymer, and especially dendritic polymer delivery carriers can but do not necessarily involve micellar formation. ${ }^{84}$ As usual, these micelles are composed of a hydrophobic core containing drugs and a hydrophilic corona modifiable by noncovalent polymer preparations for improved target specificity. ${ }^{85}$ However, no trials have been conducted in neuronal cell-specific models. Moreover, this approach can evoke complement system activation, resulting in complications similar to those of liposomes, but to a lesser degree. $^{86}$

In polymer conjugates, drugs have to covalently bind to the polymer backbone with the help of a linker, leading to stable conjugates in serum or blood. However, the conjugates can be unstable under inflammatory conditions, ${ }^{87}$ so their application may be hindered in the hyperacute or acute inflammatory period after CNS injury. Because covalent binding to the backbone copolymer can be achieved through various kinds of linkers, such as $\mathrm{pH}-$, light-, enzyme- or redox-sensitive liners, drugs can be released under the anticipated conditions. ${ }^{88}$ As a backbone material, N-(2-hydroxypropyl) methacrylamide (HPMA) has been mostly used, but it is not biodegradable. ${ }^{81}$ Moreover, just one trial has been conducted in a CNS injury model, ${ }^{89}$ so such nanocarriers require further evaluation prior to discussion as targeted carriers to the CNS.

The spray-drying technique has evolved to be applied in the manufacture of noncovalent polymer-drug nanospheres/nanocapsules since the report by Kala et al in 1979. ${ }^{90}$ Currently, polymer-entrapping or polymeradsorbing drugs can be fabricated on a surface even without the assistance of particles. ${ }^{91}$ In detail, nanospray dryers consist of a pulsating casing in a spray nozzle (to atomize the feeding materials) and an end product gathering accumulator. $^{92}$ The dried end products are retrieved from a chamber with a powder scraper. Nanospray dryers are well known to have high yields (approximately 70\%). ${ }^{93}$ Moreover, with the spray-drying technique, ${ }^{61,62,66,68}$ nanospray dryers can achieve the one-step manufacturing of EPO nanospheres/nanocapsules through noncovalent entrapment or adsorption by biodegradable polymers. ${ }^{94}$

\section{Spatiotemporal ${ }^{65}$ Magnetic Navigation}

One hundred years have passed since the "magic bullet" concept was first introduced by Paul Ehrlich. ${ }^{95}$ Various kinds of magnetic navigation systems for targeted drug delivery have evolved, and promising results have been reported; for example, greater intravenously injected drug localization was achieved using commercialized ferronanocarriers $\left(\mathrm{Fe}_{3} \mathrm{O}_{4}\right.$ superparamagnetic iron oxide nanocarriers [SPIONs]) under magnetic navigation (66.3\%) than without magnetic navigation (1\%) in a rabbit cancer model. ${ }^{87,96}$ Based on the aforementioned findings, nanocarriers can be delivered in a targeted manner to a CNS injury site and exclusively localized within the CNS injury site, permitting their escape from competitive binding to non-in situ EPO receptors. Usually, no more than five minutes are required for blood from the heart to systemically circulate throughout the whole body of adult humans one time; thus, magnetic control provides nanocarriers with approximately 100 passive chances to reach the injured area within the therapeutic time window of EPO (6-8 hours), which can even be potentiated by the dual magnetic-catalytic actions of nanocarriers. ${ }^{97}$ Once nanocarriers reach the injured area under a magnetic field, the nanocarriers may remain in situ at a high density through mutual magnetic force. However, in terms of magnetic navigation to a site of CNS injury, no trials of EPO nanocarriers ${ }^{87}$ among dozens of nanocarrier trials have been reported, so the following review involves to discussion of nanocarrier-mediated drug delivery to various organs as well as to the CNS.

Internal methods consisting of magnetic implants, eg, ferric steel placed in the subarachnoid space for intrathecal delivery, ${ }^{98}$ have been applied to reduce the systemic toxicity of nanocarriers. Epidural ferro-nanocarrier implants showed a high collection rate within the targeted area $(891 \%)$ in a human spine model. ${ }^{99}$ However, both inadequate drug delivery and invasiveness remain limitations. ${ }^{91}$ To achieve improved internal spatiotemporal navigation of administered drug-loaded ferro-nanocarriers, the combination of magnet implantation into blood vessels and the external application of a magnetic field showed a high targeted delivery rate (no less than $60 \%$ ). ${ }^{100}$ Based on Halbach arrays of magnets ${ }^{101}$ and Earnshaw's theorem, ${ }^{102}$ internally located magnetic forces could be created with dynamic magnetic fields at deep locations in vitro, ${ }^{100,103}$ such that the external application of a magnetic field for internal navigation is more relevant than before. The external application of a magnetic field has been widely investigated as a useful targeted delivery strategy for paramagnetic nanocarriers, ranging from in vitro experiments to near clinical validation studies. ${ }^{67}$ To gain high targeted delivery efficacy, a field strength of 200-700 $\mathrm{mT}$ and a gradient of $8-100 \mathrm{~T} / \mathrm{m}$ should be provided, depending on the speed of blood circulation. ${ }^{69}$ 
Additionally, the external application of a magnetic field in a pulsed (on/off) mode was preferable to that in a constant mode in a mouse Alzheimer's disease model. ${ }^{104}$ External magnetic navigation has been extended in terms of applicable forms; for instance, magnetizable aerosols can be delivered in a targeted manner to a specific area within the lungs through inhalation with the aid of nebulizers. ${ }^{105}$ Although the aforementioned results are technically promising, it may still be challenging to maintain magnetic traps more than $2 \mathrm{~cm}$ deep in animal and human tissues under the external application of a magnetic field. ${ }^{69,103}$

Similar to external magnetic field applications, external magnetic resonance navigation can be applicable. Magnetic resonance imaging (MRI) machines can easily focus the location of the magnetic field to any area within the human body with a high magnetic flux density (no less than $1.5 \mathrm{~T}$ ). If nanocarriers can be under the control of an external magnetic concentrator with the aid of multiple rewinding helix/multiangular coils, they can be delivered to a targeted area under an internally focused magnetic field. ${ }^{106}$ The direction of ferro-nanocarriers can be remotely controlled using an external magnetic field gradient at a high velocity of up to $8 \mathrm{~mm} / \mathrm{s} .{ }^{97}$ Furthermore, the swarm actuation of ferro-nanocarriers can be controlled in blood plasma or whole blood at no more than $30 \mu \mathrm{m} / \mathrm{s}$ with a $10^{\circ}$ pitch angle, and their targeted navigation has been demonstrated ex vivo in a bovine eyeball using 3-axis Helmholtz electromagnetic coils. ${ }^{107}$ In an in vivo experiment, multifunctioning drug ferro-nanocarriers could be delivered to pathological lesions within the brain under magnetic resonance navigation in a rat brain tumor model. ${ }^{108}$

For spatiotemporal magnetic navigation, any magnetic subject can be incorporated into drug delivery carriers; examples include magnetosomes in Magnetospirillum species ${ }^{109}$ and various kinds of nanocarriers. Nanocarriers of the following materials have been investigated since the report by Marty et al in 1978: ${ }^{110}$ gold, silver, carbon, and metal oxides, such as $\mathrm{TiO}_{2}, \mathrm{ZnO}, \mathrm{Fe}_{3} \mathrm{O}_{4}, \mathrm{Fe}_{2} \mathrm{O}_{3}, \mathrm{Al}_{2} \mathrm{O}_{3}$, and $\mathrm{CrO}_{3}{ }^{105,111}$ Both $\mathrm{Fe}_{3} \mathrm{O}_{4}$ and $\mathrm{Fe}_{2} \mathrm{O}_{3}$ are known to be superparamagnetic, and the others are paramagnetic. $^{67}$ As superparamagnetic nanocarriers, maghemite $\left(\gamma-\mathrm{Fe}_{2} \mathrm{O}_{3}\right)$ and magnetite $\left(\mathrm{Fe}_{3} \mathrm{O}_{4}\right)$ are most commonly used because of their good tolerance. ${ }^{107,112}$ To synthesize nanocarriers, a chemical coprecipitation method is commonly used. ${ }^{113,114}$ As alternatives, ultrasound irradiation, hydrothermal, solvothermal, microemulsion and thermal decomposition methods can be used. ${ }^{68}$ It is advantageous that nanocarriers can pass through the BBB successfully under magnetic control, as demonstrated in rat models in vivo. ${ }^{104,115}$
In the presence of organic materials such as polysaccharides and fatty acids, colloidal nanocarriers in solution exhibit the added benefit of stability during targeted delivery. Even though some of the materials listed have fairly weak magnetic properties, nanocarrier magnetization could be augmented through close proximity in the aforementioned manufacturing methods; for example, magnetization increases by no less than 5-fold in nanospheres compared to single superparamagnetic iron nanocarriers. ${ }^{116}$ As an alternative, an internally focused magnetic concentrator can be applied at a high magnetic flux density of up to $8 \mathrm{~T}$ in adults and $4 \mathrm{~T}$ in children according to the FDA guidelines. ${ }^{103,117,118}$ Furthermore, to compensate for poor navigation due to weak magnetic properties, dual magnetic-catalytic actions can be useful; for example, $\mathrm{O}_{2}$ bubbles produced by ferro-nanocarriers catalyzing the breakdown of $\mathrm{H}_{2} \mathrm{O}_{2}$ can generate trajectory propulsion of nanocarriers in biological fluids, the direction of which can be controlled by a magnetic field gradient. ${ }^{97}$ In addition to functioning as a magnetic mediator, nanocarriers can promote neuronal differentiation, improve neuronal survivability, and stimulate neuronal regrowth such that they can act as neuroregenerators or protectors by themselves. ${ }^{119}$ Moreover, the combination of EPO and nanocarriers showed a neuroprotective effect that was no less than 10-fold that of rhEPO in a hypoxic rat model. $^{64}$ The synergistic/additive effects of EPO and nanocarriers have been observed in EPO-loaded nanocarrier targeted delivery trials. ${ }^{62-64}$ Although the molecular mechanism of neuroprotection by solitary or incorporated nanocarriers has not yet been precisely elucidated, the targeted delivery of EPO using magnetic nanocarrier navigation may be a more warranted delivery method than that with other magnetic mediators, such as magnetosomes. ${ }^{120}$

Contrary to the aforementioned advantages of passive magnetic navigation, magnetotactic bacteria, such as Magnetococcus marinus $M C$-1, could be attached to drug nanocarriers for active propelling without additional propulsion appendages. This approach could be applicable in the treatment of difficult-to-reach lesions, such as hypoxic regions within solid tumors. ${ }^{121}$

\section{Characterization of Erythropoietin Nanocarriers \\ Scanning Electron Microscopy and Transmission Electron Microscopy}

Following the combination of EPO and nanocarriers, the physical characteristics of each component, such as morphology and size, can be changed. A nanocarrier can be 
visually evaluated using transmission electron microscopy (TEM) or scanning electron microscopy (SEM). For example, differences in the diameter of a ferro-nanocarrier (approximately $10 \mathrm{~nm})^{122}$ and the diameter of EPO (approximately $4.2 \mathrm{~nm})^{55,123}$ can be visualized using SEM and TEM. Furthermore, visual differentiation of EPO and nanocarriers was achieved by Beh et al using TEM. $^{124}$

\section{Fourier-Transform Infrared Spectroscopy}

With the aid of Fourier-transform infrared spectroscopy (FTIR), the adsorption of EPO on the surface of nanocapsules/ nanospheres can be confirmed by assessing the characteristic peaks; for example, the FT-IR spectrum of a ferronanocarrier shows a peak at $598-628 \mathrm{~cm}^{-1}$ for $\mathrm{Fe}-\mathrm{O}$, confirming nanoparticle adsorption. ${ }^{125,126}$ Another peak at approximately $1632 \mathrm{~cm}^{-1}$ indicates the presence of hydroxyl groups (O-H bending) on a ferro-nanocarrier. These findings confirm the presence of $\mathrm{Fe}(\mathrm{OH})_{2}$ on the nanocapsule/nanosphere surface. ${ }^{127}$ In the characteristic FT-IR spectrum of EPO, the S-H peak at $2414 \mathrm{~cm}^{-1}$ demonstrates the presence of the sulfhydryl group of free cysteine at position 31, confirming EPO adsorption on the surface. ${ }^{128}$

\section{Thermogravimetric Analysis}

For the determination of incorporation efficiency, thermal stability with phase transitions can be analyzed in terms of the portion of decomposition and weight loss using thermogravimetric analysis (TGA); for example, nanocarriers can be synthesized from inorganic materials such that no characteristic weight loss occurs. ${ }^{129}$ However, a large single weight loss step representing the decomposition of polymer chains can occur in the examination of wellentrapped polymer nanocarriers by TGA. ${ }^{130}$

\section{Methods to Monitor Effectiveness of Magnetic Navigation}

Magnetic navigation can be readily confirmed in vitro using soft lithography, especially using 2- or 3-dimensional furcated microchannels, which are commonly composed of polydimethylsiloxane and used to simulate blood vessels. ${ }^{100}$ The migration of nanocarriers coupled with fluorescent microbeads or antibodies into a chamber under a magnetic field confirms this navigation. ${ }^{94}$ As an alternative, nanocarriers can be trapped in an artificial glass capillary; for example, magnetic nanocarriers can be trapped by switching on an external magnet. ${ }^{106}$ In addition to several kinds of nonhistological in vivo approval using MRI, ${ }^{131}$ there have been few reports on ex vivo histological demonstrations of external magnetic navigation. Drugs conjugated with nanocarriers show a controllable organ distribution; for example, magnetite nanocarriers were guided into rat mesenteric microvessels, and the organ-specific distribution of magnetite nanocarriers was measured by magnetometry in a mouse model. ${ }^{106,132}$ Preferably, ex vivo necropsy should be conducted following the tagging of fluorescence microbeads or antibodies to the nanocarriers. Following the approval of external magnetic navigation methods, parameters such as the exposure time to the magnetic field, magnetic field strength $(\mathrm{A} / \mathrm{m})$, and magnetic flux density $(\mathrm{T})$ should also be optimized under in vitro/vivo conditions.

\section{Troubleshooting}

\section{Alteration in Synthetic and in vivo}

\section{Biological Identity}

\section{Thermal Stability}

During noncovalent nanocarrier manufacturing via a nanospray dryer, the temperature of the inlet is usually set to approximately $120^{\circ} \mathrm{C}$ so that the nanocarrier can undergo a heat-induced morphological alteration. ${ }^{133}$ However, the temperature of the outlet is set to approximately $40^{\circ} \mathrm{C}$, and end products are stored in a desiccator at a temperature of $25^{\circ} \mathrm{C}$, allowing them to be exposed to heat for a relatively short time at a pressure of 28 mbar. $^{93}$ EPO maintains thermal stability up to $56^{\circ} \mathrm{C}$ through carbohydrate tagging. Moreover, EPO displays reversible denaturation below $75^{\circ} \mathrm{C}$, allowing recovery of its conformational stability following cooling. ${ }^{134}$ However, confirmation of the stability of the nanocarrier/EPO conformation and preservation of the neuroprotective effects in vivo may be necessary prior to the start of clinical trials.

In vivo Aggregation and Phagocytosis by the Mononuclear Phagocyte System

Biological fluids such as serum and plasma can cause nanocarriers to aggregate in vivo. ${ }^{111}$ As a result, nanocarriers are engulfed by mononuclear phagocyte systems and removed from the body, thus prohibiting their localization to an injured area and the exertion of their neuroprotective and regenerative actions. Furthermore, nanocarrier aggregation and/or engulfment by mononuclear phagocyte systems may cause microthrombotic foci. Prior to clinical application, nanocarriers should be evaluated in terms of 
in vivo aggregation, which can be readily achieved by TEM or dynamic light scattering (DLS) using measurements of the nanocarrier size distribution following incubation in biological fluids.

Moreover, upon the exposure of nanocarriers to physiological conditions, numerous kinds of proteins quickly attach to their surface and form a protein corona. ${ }^{111,135}$ As a result, the biological identity of nanocarriers can be modified such that opsonin-marked nanocarriers are phagocytized by mononuclear phagocyte systems. ${ }^{136}$ Especially in the CNS, nanocarriers are typically engulfed by microglial cells, ${ }^{137}$ and coating nanocarriers with PEG is the most popular method to prevent nonspecific protein adherence and subsequent phagocytosis. ${ }^{138}$ Similarly, various kinds of polymer coatings may be useful to prohibit the removal of nanocarriers by mononuclear phagocyte systems before they approach the targeted area. ${ }^{136}$

\section{Spontaneous or Artificial Degradation of Nanocarriers into Subcomponents}

To date, the targeted delivery of EPO represents a departure from approaches focusing on the sustained, slow release of EPO from nanocarriers in most trials. $^{57,58,62}$ Whereas most EPO nanocarriers spontaneously break down, the noncovalent crosslinking stability of an EPO polymer can be maintained for a very long time; for example, this stability can be maintained for up to 8 weeks in the case of EPO entrapped in gelatin microspheres. ${ }^{139}$ In contrast, the half-life of conventional rhEPO is $6-8$ hours, ${ }^{140}$ and the peak presence of rhEPO in the cerebrospinal fluid (CSF) occurs 2 hours after intravenous administration. ${ }^{53}$ For optimal neuroprotection or regeneration, both the spontaneous breakdown of nanocarriers and the physiological nature of EPO must be balanced simultaneously.

Electrical charge can accumulate in specific solid materials such as crystals and ceramics in response to an applied mechanical force; this is known as the piezoelectric effect. ${ }^{141}$ This phenomenon can occur in nanocarriers such that electrical energy can be harvested from compressive stress. ${ }^{142,143}$ Similar to heat production by ultrasonic waves during physiotherapies, the inverse piezoelectric effect can be induced, leading to heat production. The alternation of a high-frequency magnetic field potentially produces motion among nanocarriers. ${ }^{138}$ Through this kind of inverse piezoelectric effect, the rapid movement of nanocarriers creates internal heat (thermal conversion), ${ }^{137}$ which can weaken the strength of noncovalent polymer crosslinking and accelerate the degradation rate, ${ }^{133,144}$ thus allowing for potential control over the EPO release rate. Moreover, the application of an alternating magnetic field over only the target area can prohibit the unintended breakdown of nanocarriers by heat conversion at non-in situ areas during delivery. As an alternative to thermal conversion, preconditioned sonication can be utilized, but this weakens the stability of noncovalent polymer crosslinking, resulting in release earlier than expected. ${ }^{145}$

However, prior to clinical application, parameters such as intensity (W) and exposure time should be optimized depending on the type of biodegradable polymer and whether the nanocarrier is being utilized under in vitro or in vivo conditions.

\section{Removal of Nanocarriers by the Mononuclear Phagocyte System After Breakdown}

Due to the foreign body nature of nanocarriers, they should be removed from the body following breakdown of the EPO nanocarriers. Because the same cell-surface receptors responsible for macrophage phagocytosis are expressed by J774A.1 cells, they have been widely used as a model for pathogen clearance. ${ }^{146}$ The total phagocytosis rate of nanocarriers compared to that of EPO nanocarrier formulations can be calculated by inductively coupled plasma atomic emission spectroscopy. ${ }^{147}$ However, phagocytosis is only a potential step in the process and does not equate with elimination. There have yet to be reports on the complete elimination of nanocarriers from the human body.

\section{Biological Requirements for High Bioavailability Treatment Passage Through the Lung Capillaries}

For systemic redistribution from the left ventricle, every EPO nanocarrier must be sufficiently small to pass through the lung capillaries. The lung capillary diameter varies depending on the species as follows: 3.0 to $13.0 \mu \mathrm{m}$ in mice and rats and approximately $6.3 \mu \mathrm{m}$ in humans. ${ }^{148,149}$ As nanomaterials, nanocarriers measure from dozens to hundreds of nanometers in size ${ }^{85}$ for example, the diameter of a ferro-nanocarrier not approved for magnetic navigation is approximately $10 \mathrm{~nm}$ in vivo ${ }^{122}$ or $30 \mathrm{~nm}$ in vitro, ${ }^{76}$ and that of one approved for magnetic resonance or magnet-assisted navigation is $20-30 \mathrm{~nm}$ in vitro150 or up to $100 \mathrm{~nm}$ in vivo. ${ }^{116}$ rhEPO is a light glycoprotein that is very small in size $(30,400 \mathrm{Da}),{ }^{55}$ and its minimum diameter has been calculated to be $4.2 \mathrm{~nm}$ 
using Erickson's equation. ${ }^{123}$ Regarding assembled products, the diameter of ferro-nanocarriers encapsulated by carboxymethyl chitosan was $500-600 \mathrm{~nm}$ in vitro. ${ }^{150}$ The mean diameter of EPO ferro-nanocarriers was approximately $500 \mathrm{~nm}(100-875 \mathrm{~nm}) .{ }^{94}$ Both of these materials were approved for magnetic navigation. Therefore, the diameter of EPO nanocarriers is expected to be much smaller than that of lung capillaries. However, on the one hand, it is important that the nanocarriers are small enough to be efficiently distributed to the tissues; on the other hand, it is important to remember that a certain amount of iron should be incorporated in order to allow responsiveness to the magnetic field. ${ }^{151}$ Iron is the component that is mainly implicated in causing the enlargement of the core of paramagnetic nanocarriers.

\section{Passage Through the Blood Brain Barrier}

To bind in situ EPO receptors inside the brain or spinal cord, BBB penetration after entering the systemic circulation is required. Following intravenous administration, EPO was observed in the same amounts as simultaneously injected mannitol for up to 8 hours in the CSF through the cisterna magna in a rat model. ${ }^{53}$ Furthermore, chemical group-tagged EPO can also penetrate the BBB; for example, carbamylated EPO has been observed in the CSF for 4 to 24 hours following intravenous injection in a rat model. ${ }^{54}$ Similar to EPO, nanocarriers can be transported through the BBB spontaneously in rat or mouse models in vivo; ${ }^{115,152}$ for example, gold nanocarriers were observed at levels of $0.3-0.6 \mu \mathrm{g} / 1 \mathrm{~g}$ brain tissue/1 $\mathrm{mg}$ nanocarrier (up to 3.2 $\mu \mathrm{g})$ in the frontal cortex, hippocampus and hypothalamus 24 hours after intraabdominal injection and $0.16 \mathrm{mg} / \mathrm{L} / 60-105 \mathrm{mg}$ nanocarrier in CSF 6 hours after injection in rats. ${ }^{115}$ In addition, the BBB penetration of nanocarriers can be augmented with the aid of receptor targeting ${ }^{153}$ or the application of implanted or external magnets ${ }^{67,104,116}$ or externally focused ultrasound ${ }^{154}$ in rat or mouse models in vivo. Furthermore, nanocarriers such as solid lipid nanoparticles, liposomes, and polymeric micelles are also known to transport drugs to the brain. ${ }^{115}$ However, their limited BBB penetrability may confer them with an insufficient capacity to transport EPO to the brain. Further, efficient applicability in humans remains to be studied because nanocarrier dimensions can still be too big for crossing the BBB without eliciting side effects, such as further neuroinflammation.

\section{Hemotoxicity, Neurotoxicity, and Systemic Toxicity}

Carbamylated EPO does not bind to hematopoietic EPO receptors, and hematopoietic activity can be precluded ${ }^{151}$ while neuroprotection is still provided in a cerebral infarction rat model. ${ }^{54}$ Therefore, hematological complications can be avoided through the use of tagging chemical groups onto EPO. As an alternative to carbamylated EPO, mutant EPO (EpoR76E and EpoS71E), ${ }^{155}$ EPO without sialic acid, ${ }^{37}$ or synthetic EPO (Epobis) ${ }^{156}$ can be tried.

To investigate the in vitro neurotoxicity of drug nanocarriers, the SH-SY5Y line, a human-derived neuronal cell line, has been commonly used, ${ }^{157}$ while PC12 and microglial cell lines can be used as alternatives. Measurements of neurotoxicity may be needed in both the form of solution and particles. Moreover, irrespective of its wellknown neuroprotective actions, a high concentration of EPO beyond a certain limit can be cytotoxic. ${ }^{11,19,158}$ Although EPO exhibited the dose-dependent neuroprotection of spinal neurons, cortical neurons, and hippocampal neurons up to $100 \mathrm{IU}$, a higher concentration (200-300 IU) exerted impaired effects. ${ }^{11,158}$ Considering several reports, the optimal concentration of EPO for nanocarrier fabrication under in vitro conditions is approximately $10 \mathrm{IU} / \mathrm{mL}$ $(0.000084 \mathrm{mg} / \mathrm{mL}) .{ }^{46-49}$ However, the amount of neuroprotection or regeneration provided by EPO is dependent on the nature of neuronal cell injury. Furthermore, the threshold may be dependent on numerous variables, such as the cell type, in vitro/in vivo experiment type, and species type. ${ }^{48}$ Individualization may be needed in every in vivo trial in vertebrates, especially humans. Regarding the in vitro/in vivo neurotoxicity of nanocarriers, neuroinhibitory effects of several kinds of nanocarriers (silver nitrate, copper oxide, graphene, quantum dots, and carbon nanotubes) have been observed in neural and neuroprogenitor cells and rat and mouse models such that increased neuronal damage and decreased neuronal population can occur. $^{119}$

In terms of the in vitro cytotoxicity of EPO nanocarriers, biodegradable polymers and EPO have been widely applied in humans. However, literature documenting concern regarding the cytotoxicity of nanocarriers has been increasing; ${ }^{157,159}$ for example, ferro-nanocarriers at a density of $100 \mathrm{mg} / \mathrm{L}$ showed $5 \%$ lethality after 24 hours of incubation in cell models of parasitic species. ${ }^{122,133}$ Although it has been claimed that there is no systemic toxicity from granular biodurable 
nanocarriers, ${ }^{160}$ many studies showing concern regarding the in vivo systemic toxicity of nanocarriers have been performed. ${ }^{159}$ For the systemic toxicity of nanocarriers, many kinds of physicochemical and molecular mechanisms are involved; for instance, altered intracellular calcium homeostasis and oxidative stress-mediated cellular events lead to cell proliferation suppression, cell cycle interference, and cell damage. ${ }^{161,162}$ Moreover, the presence of nanocarriers may cause immune reactions in the $\mathrm{CNS},{ }^{137}$ which may need to be tested in various cell types, as no details regarding cell type were reported.

Regarding the in vivo systemic toxicity of EPO nanocarriers, the following model organisms have been tested: yeast (Saccharomyces), Drosophila, Caenorhabditis elegans, zebrafish, mice, and monkeys. ${ }^{163}$ Among vertebrate organism models, zebrafish, vertebrates with highly conserved signaling pathways and genomic homology with humans (approximately 75\% similarity), have recently gained popularity. ${ }^{163,164}$ The hatching of zebrafish eggs is very rapid, and their larvae can feed themselves 120 hours after fertilization. ${ }^{165}$ Because of the transparent embryos, the organs are readily observable in vivo from the initial larval stages. ${ }^{166}$ Several techniques can be explored, such as analyzing hatching achievement, observing organ and embryo malformation in development, in vivo imaging using microcomputed tomography, examining live biosensors such as the skin and gills, and analyzing swimming behavioral kinetics, reproduction, genotoxicity, neurotoxicity, and immunotoxicity. ${ }^{163}$ Finally, ex vivo necropsy should be conducted depending on the hematopoietic and nonhematopoietic systems to evaluate the tissue/organdependent deposit rate and tissue toxicity of the EPO nanocarriers.

\section{Future Outlook}

In 2013, approximately 7.6 billion US dollars were spent on the nanotechnology business, and this number is expected to increase to 1 trillion US dollars in $2020 .^{167}$ Moreover, 1814 nanoparticle products were commercialized by $2013 .{ }^{168}$ However, in terms of medically commercialized application for human beings, their disadvantages (scale up, human safety, technical limitations, regulatory policies, etc.) must be remedied prior to Food and Drug Administration (FDA) and European Medicines Agency (EMEA) approval. Although the concept of magnetic navigation in medicine was suggested by Freeman in $1960,{ }^{169}$ related technologies have been utilized since the 2010s. Despite numerous studies reporting successful magnetic nanocarrier-mediated targeted drug delivery, none reach beyond the feasibility or proof-of-concept due to this technical limitation, and the majority of in vivo trials remain restricted to smallanimal models. To date, only a few medical trials using magnetic nanocarriers are ongoing; among them, few trials are being conducted in patients with CNS diseases, and no trials of targeted EPO delivery are being conducted. ${ }^{103}$ Apart from targeted drug delivery, no commercialized magnetic nanocarriers have successfully been applied to humans except for several iron oxide nanocarriers (SPION compounds: Feridex ${ }^{\circledR}$ in the USA [Berlex Laboratories], Endorem ${ }^{\mathrm{TM}}$ in the EU [Guerbet S. L.], Resovist ${ }^{\circledR}$ in the EU [Bayer Healthcare], Combidex ${ }^{\circledR}$ in the USA [AMAG Pharmaceuticals], etc.), which were approved for only diagnostic aids and not for therapeutic treatment. $^{67,170}$ Nonetheless, approval of Rienso ${ }^{\circledR} /$ Feraheme $^{\circledR}$ for intravenous replacement of iron in patients with chronic renal failure may provide a good chance to monitor the systemic toxicity of nanocarriers. $^{120}$ For technical handicaps, maintaining a constant magnetic field in deep tissues in a precise manner will be another challenging issue regarding the magnetic navigation of EPO nanocarrier complexes. To overcome these complicated barriers to commercialization, multimodal disciplinary research team consisting of doctors, chemicophysicists, biologists, bioengineers, and pharmacologists is warranted to determine the ideal parameters (nanocarrier type, dosage, delivery/navigation hardware, etc.). Finally, regulatory policies for these products, which are highly variable among countries, ranging from no regulation (neither drug nor medical equipment in very undeveloped countries) to no permission (either very limited drug approval or no approved medical equipment in the EU and the USA), are another handicap that must be remedied for successful commercialization.

\section{Conclusion}

EPO is known to function as both a neuroprotector and neuroregenerator. However, its clinical use is very difficult due to its very short therapeutic time window (within 6-8 hours), its heterogeneity and phylogenetic differences among the EPO receptors. To overcome these drawbacks, targeted delivery carriers have been under development. For carrier manufacturing, the noncovalent crosslinking of EPO polymers using the nanospraydrying technique that can be performed with ease is of 
great interest. For externally controlled EPO delivery within the therapeutic time window, magnetic navigation following coupling with magnetic nanocarriers may be a promising method. Nonetheless, it should be determined how EPO nanocarriers can be selectively delivered to the site of CNS injury (and not surrounding tissue) using an internally/externally applied magnetic field. Prior to clinical trials, manufactured EPO nanocarriers must be characterized in terms of their in vivo size distribution and high efficiency of incorporation. The following issues remain challenges for achieving a high degree of therapeutic bioavailability: alteration of in vivo biological identities, such as protein corona formation; a sufficiently small size to pass through the lung capillaries or the BBB; timely carrier degradation followed by removal from the body; and avoidance of binding to non-in situ EPO receptors with heterogeneity and phylogenetic differences. Problems regarding the hematological complications, neurotoxicity, and cytotoxicity of EPO nanocarriers and their degraded subcomponents should also be solved. These challenges lay the foundation for the development of a new treatment paradigm for patients with CNS injuries and for the incorporation of a variety of therapeutic agents in the future, with the expectation of fast targeted delivery in vivo and exclusive localization at a high density.

\section{Abbreviations}

EPO, erythropoietin; rhEPO, recombinant human EPO; CNS, central nervous system; BBB, blood brain barrier; TEM, transmission electron microscopy; SEM, scanning electron microscopy; FT-IR, Fourier-transform infrared spectroscopy; CSF, cerebrospinal fluid; SPION, superparamagnetic iron oxide nanocarrier.

\section{Acknowledgments}

I like to thank Na-Young Joo for general assistance in gathering the references.

\section{Author Contributions}

CRediT roles of Chang Ho Hwang: Conceptualization; Funding acquisition; Investigation; Methodology; Project administration; Resources; Visualization; Roles/Writing original draft; Writing - review and editing.

\section{Funding}

This work was supported by a National Research Foundation of Korea (NRF: https://www.nrf.re.kr/index) grant funded by the Korean government (Ministry of Science, ICT \& Future Planning) (NRF-2017R1A2B4011478).

\section{Disclosure}

The author reports no conflicts of interest in this work.

\section{References}

1. Storring PL, Tiplady RJ, Gaines Das RE, et al. Epoetin alfa and beta differ in their erythropoietin isoform compositions and biological properties. Br J Haematol. 1998;100(1):79-89.

2. Murua A, Orive G, Hernandez RM, Pedraz JL. Emerging technologies in the delivery of erythropoietin for therapeutics. Med Res Rev. 2011;31(2):284-309.

3. Buemi M, Caccamo C, Nostro L, Cavallaro E, Floccari F, Grasso G. Brain and cancer: the protective role of erythropoietin. Med Res Rev. 2005;25(2):245-259.

4. Shoemaker CB, Mitsock LD. Murine erythropoietin gene: cloning, expression, and human gene homology. Mol Cell Biol. 1986;6(3):849-858. doi:10.1128/MCB.6.3.849

5. Nagao M, Suga H, Okano M, et al. Nucleotide sequence of rat erythropoietin. Biochim Biophys Acta. 1992;1171(1):99-102. doi:10.1016/0167-4781(92)90146-Q

6. Lin FK, Lin $\mathrm{CH}$, Lai PH, et al. Monkey erythropoietin gene: cloning, expression and comparison with the human erythropoietin gene. Gene. 1986;44(2-3):201-209. doi:10.1016/03781119(86)90183-6

7. Pearse D, Jarnagin K. Abating progressive tissue injury and preserving function after CNS trauma: the role of inflammation modulatory therapies. Curr Opin Investig Drugs. 2010;11 (11):1207-1210.

8. Juul S. Erythropoietin in the central nervous system, and its use to prevent hypoxic-ischemic brain damage. Acta Paediatr Suppl. 2002;91(438):36-42. doi:10.1111/j.1651-2227.2002.tb02904.x

9. Matis GK, Birbilis TA. Erythropoietin in spinal cord injury. Eur Spine J. 2009;18(3):314-323. doi:10.1007/s00586-008-0829-0

10. Vitellaro-Zuccarello L, Mazzetti S, Madaschi L, Bosisio P, Gorio A, De Biasi S. Erythropoietin-mediated preservation of the white matter in rat spinal cord injury. Neuroscience. 2007;144(3):865-877. doi:10.1016/j.neuroscience.2006.10.023

11. Morishita E, Masuda S, Nagao M, Yasuda Y, Sasaki R. Erythropoietin receptor is expressed in rat hippocampal and cerebral cortical neurons, and erythropoietin prevents in vitro glutamate-induced neuronal death. Neuroscience. 1997;76 (1):105-116. doi:10.1016/S0306-4522(96)00306-5

12. Cho YK, Kim G, Park S, et al. Erythropoietin promotes oligodendrogenesis and myelin repair following lysolecithin-induced injury in spinal cord slice culture. Biochem Biophys Res Commun. 2012;417(2):753-759. doi:10.1016/j.bbrc.2011.12.029

13. Eid T, Brines M. Recombinant human erythropoietin for neuroprotection: what is the evidence? Clin Breast Cancer. 2002;3 (Suppl 3):S109-115. doi:10.3816/CBC.2002.s.021

14. Lu B, Huang P. [Calculation of specific evolution rate of proteins based on phylogenetic]. Yi Chuan Xue Bao = Acta Genetica Sinica. 1996;23(2):85-90. Chinese.

15. Ocampo Daza D, Larhammar D. Evolution of the receptors for growth hormone, prolactin, erythropoietin and thrombopoietin in relation to the vertebrate tetraploidizations. Gen Comp Endocrinol. 2018;257:143-160. doi:10.1016/j.ygcen.2017.06.021

16. Nunomura W, Cianciarullo AM, Kato T, Shimizu R, Witeska M. Phylogeny and ontogeny of erythropoiesis. Biomed Res Int. 2015;2015:136270. doi:10.1155/2015/136270 
17. Dumont F, Bischoff P. Non-erythropoietic tissue-protective peptides derived from erythropoietin: WO2009094172. Expert Opin Ther Pat. 2010;20(5):715-723. doi:10.1517/13543771003627464

18. Hahn N, Büschgens L, Schwedhelm-Domeyer N, et al. The orphan cytokine receptor CRLF3 emerged with the origin of the nervous system and is a neuroprotective erythropoietin receptor in locusts. Front Mol Neurosci. 2019;12:251. doi:10.3389/ fnmol.2019.00251

19. Hong HN, Shim JH, Won YJ, Yoo JY, Hwang CH. Therapeutic time window for the effects of erythropoietin on astrogliosis and neurite outgrowth in an in vitro model of spinal cord injury. Medicine. 2018;97(9):e9913. doi:10.1097/MD.000000 0000009913

20. Wu SK, Yang MT, Kang KH, et al. Targeted delivery of erythropoietin by transcranial focused ultrasound for neuroprotection against ischemia/reperfusion-induced neuronal injury: a long-term and short-term study. PLoS One. 2014;9(2):e90107. doi:10.1371/journal.pone. 0090107

21. Kwon BK, Okon EB, Plunet W, et al. A systematic review of directly applied biologic therapies for acute spinal cord injury. J Neurotrauma. 2011;28(8):1589-1610. doi:10.1089/ neu.2009.1150

22. Fitch MT, Silver J. CNS injury, glial scars, and inflammation: inhibitory extracellular matrices and regeneration failure. Exp Neurol. 2008;209(2):294-301. doi:10.1016/j.expneurol.200 7.05.014

23. Silver J, Miller JH. Regeneration beyond the glial scar. Nat Rev Neurosci. 2004;5(2):146-156. doi:10.1038/nrn1326

24. Voskuhl RR, Peterson RS, Song B, et al. Reactive astrocytes form scar-like perivascular barriers to leukocytes during adaptive immune inflammation of the CNS. J Neurosci. 2009;29 (37):11511-11522. doi:10.1523/JNEUROSCI.1514-09.2009

25. Dergham P, Ellezam B, Essagian C, Avedissian H, Lubell WD, McKerracher L. Rho signaling pathway targeted to promote spinal cord repair. $J$ Neurosci. 2002;22(15):6570-6577. doi:10.1523/JNEUROSCI.22-15-06570.2002

26. Arocho LC, Figueroa JD, Torrado AI, Santiago JM, Vera AE, Miranda JD. Expression profile and role of EphrinA1 ligand after spinal cord injury. Cell Mol Neurobiol. 2011;31(7):1057-1069. doi:10.1007/s10571-011-9705-2

27. Chan CC, Wong AK, Liu J, Steeves JD, Tetzlaff W. ROCK inhibition with Y27632 activates astrocytes and increases their expression of neurite growth-inhibitory chondroitin sulfate proteoglycans. Glia. 2007;55(4):369-384. doi:10.1002/glia.20466

28. Puschmann TB, Turnley AM. Eph receptor tyrosine kinases regulate astrocyte cytoskeletal rearrangement and focal adhesion formation. J Neurochem. 2010;113(4):881-894.

29. Zhang Y, Zhang J, Navrazhina K, et al. TGFbetal induces Jagged1 expression in astrocytes via ALK5 and Smad3 and regulates the balance between oligodendrocyte progenitor proliferation and differentiation. Glia. 2010;58(8):964-974.

30. Zode GS, Sethi A, Brun-Zinkernagel AM, Chang IF, Clark AF, Wordinger RJ. Transforming growth factor-beta2 increases extracellular matrix proteins in optic nerve head cells via activation of the Smad signaling pathway. Mol Vis. 2011;17:1745-1758.

31. Buss A, Pech K, Kakulas BA, et al. TGF-beta1 and TGF-beta2 expression after traumatic human spinal cord injury. Spinal Cord. 2008;46(5):364-371. doi:10.1038/sj.sc.3102148

32. Venkatesan N, Uchino K, Amagase K, Ito Y, Shibata N, Takada K. Gastro-intestinal patch system for the delivery of erythropoietin. J Control Release. 2006;111(1-2):19-26. doi:10.1016/j.jconrel.2005.11.009

33. Lejnieks DV, Ramesh N, Lau S, Osborne WR. Stomach implant for long-term erythropoietin expression in rats. Blood. 1998;92 (3):888-893. doi:10.1182/blood.V92.3.888
34. Schwenter F, Schneider BL, Pralong WF, Deglon N, Aebischer P. Survival of encapsulated human primary fibroblasts and erythropoietin expression under xenogeneic conditions. Hum Gene Ther. 2004;15(7):669-680. doi:10.1089/1043034041361172

35. Kang CE, Poon PC, Tator CH, Shoichet MS. A new paradigm for local and sustained release of therapeutic molecules to the injured spinal cord for neuroprotection and tissue repair. Tissue Eng Part A. 2009;15(3):595-604. doi:10.1089/ten.tea.2007.0349

36. Geng Y, Yuan W, Wu F, Chen J, He M, Jin T. Formulating erythropoietin-loaded sustained-release PLGA microspheres without protein aggregation. $J$ Control Release. 2008;130 (3):259-265. doi:10.1016/j.jconrel.2008.06.011

37. Garcia-Rodriguez JC, Sosa-Teste I. The nasal route as a potential pathway for delivery of erythropoietin in the treatment of acute ischemic stroke in humans. TheScientificWorldJournal. 2009;9:970-981. doi:10.1100/tsw.2009.103

38. Akilo OD, Choonara YE, Strydom AM, et al. An in vitro evaluation of a carmustine-loaded Nano-co-Plex for potential magnetic-targeted intranasal delivery to the brain. Int $J$ Pharm. 2016;500(1-2):196-209. doi:10.1016/j.ijpharm.2016.01.043

39. Chauhan MB, Chauhan NB. Brain uptake of neurotherapeutics after intranasal versus intraperitoneal delivery in mice. $J$ Neurol Neurosurg. 2015;2(1). doi:10.19104/jnn.2015.91

40. Santos-Morales O, Díaz-Machado A, Jiménez-Rodríguez D, et al. Nasal administration of the neuroprotective candidate NeuroEPO to healthy volunteers: a randomized, parallel, open-label safety study. BMC Neurol. 2017;17(1):129.

41. Bijani C, Arnarez C, Brasselet S, et al. Stability and structure of protein-lipoamino acid colloidal particles: toward nasal delivery of pharmaceutically active proteins. Langmuir. 2012;28 (13):5783-5794. doi:10.1021/1a300222v

42. Laursen T, Grandjean B, Jørgensen JO, Christiansen JS. Bioavailability and bioactivity of three different doses of nasal growth hormone $(\mathrm{GH})$ administered to GH-deficient patients: comparison with intravenous and subcutaneous administration. Eur $J$ Endocrinol. 1996;135(3):309-315. doi:10.1530/ eje. 0.1350309

43. Fletcher L, Kohli S, Sprague SM, et al. Intranasal delivery of erythropoietin plus insulin-like growth factor-I for acute neuroprotection in stroke. Laboratory investigation. $J$ Neurosurg. 2009;111(1):164-170. doi:10.3171/2009.2.JNS081199

44. Lagarto A, Bueno V, Sanchez JA, et al. Short-term intra-nasal erythropoietin administration with low sialic acid content is without toxicity or erythropoietic effects. Curr Neurovasc Res. 2012;9 (4):233-238. doi:10.2174/156720212803530645

45. Teste IS, Tamos YM, Cruz YR, et al. Dose effect evaluation and therapeutic window of the neuro-EPO nasal application for the treatment of the focal ischemia model in the Mongolian gerbil. TheScientificWorldJournal. 2012;2012:607498. doi:10.1100/ 2012/607498

46. Li G, Ma R, Huang C, et al. Protective effect of erythropoietin on beta-amyloid-induced $\mathrm{PC} 12$ cell death through antioxidant mechanisms. Neurosci Lett. 2008;442(2):143-147. doi:10.1016/j. neulet.2008.07.007

47. Zhi-Kun S, Hong-Qi Y, Zhi-Quan W, Jing P, Zhen H, Sheng-Di C Erythropoietin prevents $\mathrm{PC} 12$ cells from beta-amyloid-induced apoptosis via PI3KAkt pathway. Transl Neurodegener. 2012;1 (1):7. doi:10.1186/2047-9158-1-7

48. Wu Y, Shang Y, Sun S, Liu R. Antioxidant effect of erythropoietin on 1-methyl-4-phenylpyridinium-induced neurotoxicity in PC12 cells. Eur $J$ Pharmacol. 2007;564(1-3):47-56. doi:10.1016/j.ejphar.2007.02.020

49. Ma R, Xiong N, Huang C, et al. Erythropoietin protects PC12 cells from beta-amyloid(25-35)-induced apoptosis via PI3K/Akt signaling pathway. Neuropharmacology. 2009;56(6-7):1027-1034. doi:10.1016/j.neuropharm.2009.02.006 
50. Baldwin PA, Klingbeil CK, Grimm CJ, Longenecker JP. The effect of sodium tauro-24,25-dihydrofusidate on the nasal absorption of human growth hormone in three animal models. Pharm Res. 1990;7(5):547-552. doi:10.1023/A:1015885204249

51. Marttin E, Verhoef JC, Romeijn SG, Merkus FW. Effects of absorption enhancers on rat nasal epithelium in vivo: release of marker compounds in the nasal cavity. Pharm Res. 1995;12 (8):1151-1157. doi:10.1023/A:1016207809199

52. Merkus FWHM, Schipper NGM, Hermens WAJJ, Romeijn SG, Verhoef JC. Absorption enhancers in nasal drug delivery - efficacy and safety. $J$ Control Release. 1993;24:201-208. doi:10.1016/0168-3659(93)90179-9

53. Ceaglio N, Orozco G, Etcheverrigaray M, et al. High performance collection of cerebrospinal fluid in rats: evaluation of erythropoietin penetration after osmotic opening of the blood-brain barrier. J Neurosci Methods. 2013;219(1):70-75. doi:10.1016/j.jneumeth.2013.07.009

54. Leist M, Ghezzi P, Grasso G, et al. Derivatives of erythropoietin that are tissue protective but not erythropoietic. Science. 2004;305 (5681):239-242. doi:10.1126/science.1098313

55. Fisher JW. Erythropoietin: physiology and pharmacology update. Exp Biol Med. 2003;228(1):1-14. doi:10.1177/153537020322800101

56. Jelkmann $\mathrm{W}$. The enigma of the metabolic fate of circulating erythropoietin (Epo) in view of the pharmacokinetics of the recombinant drugs rhEpo and NESP. Eur J Haematol. 2002;69 (5-6):265-274. doi:10.1034/j.1600-0609.2002.02813.x

57. Zhang W, Zhou G, Gao Y, et al. A sequential delivery system employing the synergism of EPO and NGF promotes sciatic nerve repair. Colloids Surf B Biointerfaces. 2017;159:327-336. doi:10.1016/j.colsurfb.2017.07.088

58. Zhang W, Gao Y, Zhou Y, et al. Localized and sustained delivery of erythropoietin from PLGA microspheres promotes functional recovery and nerve regeneration in peripheral nerve injury. Biomed Res Int. 2015;2015:478103.

59. Lippi G, Franchini M, Favaloro EJ. Thrombotic complications of erythropoiesis-stimulating agents. Semin Thromb Hemost. 2010;36(5):537-549. doi:10.1055/s-0030-1255448

60. Patel GM, Patel GC, Patel RB, Patel JK, Patel M. Nanorobot: a versatile tool in nanomedicine. J Drug Target. 2006;14 (2):63-67. doi:10.1080/10611860600612862

61. Wang Y, Cooke MJ, Morshead CM, Shoichet MS. Hydrogel delivery of erythropoietin to the brain for endogenous stem cell stimulation after stroke injury. Biomaterials. 2012;33 (9):2681-2692. doi:10.1016/j.biomaterials.2011.12.031

62. Fayed BE, Tawfik AF, Yassin AE. Novel erythropoietin-loaded nanoparticles with prolonged in vivo response. J Microencapsul. 2012;29(7):650-656. doi:10.3109/02652048.2012.680507

63. He N, Wang T, Jiang L, Wang D, Hu Y, Zhang L. Therapy for cerebral ischemic injury with erythropoietin-containing nanoparticles. J Nanosci Nanotechnol. 2010;10(8):5320-5323. doi:10.1166/jnn.2010.3032

64. Chen H, Spagnoli F, Burris M, et al. Nanoerythropoietin is 10-times more effective than regular erythropoietin in neuroprotection in a neonatal rat model of hypoxia and ischemia. Stroke. 2012;43(3):884-887. doi:10.1161/STROKEAHA.111.637090

65. Jeong JH, Kang SH, Kim DK, Lee NS, Jeong YG, Han SY. Protective effect of cholic acid-coated Poly Lactic-Co-Glycolic Acid (PLGA) nanoparticles loaded with erythropoietin on experimental stroke. J Nanosci Nanotechnol. 2019;19(10):6524-6533. doi:10.1166/jnn.2019.17078

66. Michel Vert YD, Hellwich KH, Hess M, et al. Terminology for biorelated polymers and applications (IUPAC Recommendations 2012). Pure Appl Chem. 2012;84(2):377-410.

67. D'Agata F, Ruffinatti FA, Boschi S, et al. Magnetic nanoparticles in the central nervous system: targeting principles, applications and safety issues. Molecules (Basel, Switzerland). 2017;23(1):9. doi:10.3390/molecules23010009
68. Busquets MA, Espargaró A, Sabaté R, Estelrich J. Magnetic nanoparticles cross the blood-brain barrier: when physics rises to a challenge. Nanomaterials (Basel, Switzerland). 2015;5 (4):2231-2248. doi:10.3390/nano5042231

69. Estelrich J, Escribano E, Queralt J, Busquets MA. Iron oxide nanoparticles for magnetically-guided and magnetically-responsive drug delivery. Int J Mol Sci. 2015;16 (12):8070-8101. doi:10.3390/ijms16048070

70. Knop K, Hoogenboom R, Fischer D, Schubert US. Poly(ethylene glycol) in drug delivery: pros and cons as well as potential alternatives. Angewandte Chemie. 2010;49(36):6288-6308. doi:10.1002/anie.200902672

71. He Q, Liu J, Liang J, et al. Towards Improvements for penetrating the blood-brain barrier-recent progress from a material and pharmaceutical perspective. Cells. 2018;7(4):24. doi:10.3390/ cells 7040024

72. Kumari A, Yadav SK, Yadav SC. Biodegradable polymeric nanoparticles based drug delivery systems. Colloids Surf $B$ Biointerfaces. 2010;75(1):1-18. doi:10.1016/j.colsurfb.200 9.09.001

73. Katas H, Raja MA, Lam KL. Development of chitosan nanoparticles as a stable drug delivery system for protein/siRNA. Int J Biomater. 2013;2013:146320. doi:10.1155/2013/146320

74. Ravikumar P, Menon JU, Punnakitikashem P, et al. Nanoparticle facilitated inhalational delivery of erythropoietin receptor cDNA protects against hyperoxic lung injury. Nanomed Nanotechnol Biol Medi. 2016;12(3):811-821. doi:10.1016/j.nano.2015.10.004

75. Huq T, Salmieri S, Khan A, et al. Nanocrystalline cellulose (NCC) reinforced alginate based biodegradable nanocomposite film. Carbohydr Polym. 2012;90(4):1757-1763. doi:10.1016/j. carbpol.2012.07.065

76. Li G, Cao L, Zhou Z, Chen Z, Huang Y, Zhao Y. Rapamycin loaded magnetic $\mathrm{Fe} 3 \mathrm{O} 4$ /carboxymethylchitosan nanoparticles as tumor-targeted drug delivery system: synthesis and in vitro characterization. Colloids Surf B Biointerfaces. 2015;128:379-388. doi:10.1016/j.colsurfb.2015.02.035

77. Unterweger H, Tietze R, Janko C, et al. Development and characterization of magnetic iron oxide nanoparticles with a cisplatin-bearing polymer coating for targeted drug delivery. Int J Nanomedicine. 2014;9:3659-3676. doi:10.2147/IJN.S63433

78. Zaloga J, Janko C, Nowak J, et al. Development of a lauric acid/ albumin hybrid iron oxide nanoparticle system with improved biocompatibility. Int $J$ Nanomedicine. 2014;9:4847-4866. doi:10.2147/IJN.S68539

79. Metselaar JM, Mastrobattista E, Storm G. Liposomes for intravenous drug targeting: design and applications. Mini Rev Med Chem. 2002;2(4):319-329. doi:10.2174/1389557023405873

80. Kuznetsova NR, Sevrin C, Lespineux D, et al. Hemocompatibility of liposomes loaded with lipophilic prodrugs of methotrexate and melphalan in the lipid bilayer. $J$ Control Release. 2012;160 (2):394-400. doi:10.1016/j.jconrel.2011.12.010

81. Hosseini SH, Maleki A, Eshraghi HR, Hamidi M. Preparation and in vitro/pharmacokinetic/pharmacodynamic evaluation of a slow-release nano-liposomal form of prednisolone. Drug Deliv. 2016;23(8):3008-3016. doi:10.3109/10717544.2016.1138341

82. Tentillier N, Etzerodt A, Olesen MN, et al. Anti-inflammatory modulation of microglia via CD163-targeted glucocorticoids protects dopaminergic neurons in the 6-OHDA Parkinson's disease model. J Neurosci. 2016;36(36):9375-9390. doi:10.1523/ JNEUROSCI.1636-16.2016

83. Tiebosch IA, Crielaard BJ, Bouts MJ, et al. Combined treatment with recombinant tissue plasminogen activator and dexamethasone phosphate-containing liposomes improves neurological outcome and restricts lesion progression after embolic stroke in rats. $J$ Neurochem. 2012;123(Suppl 2):65-74. doi:10.1111/j.14714159.2012.07945.x 
84. Li F, Snow-Davis C, Du C, Bondarev ML, Saulsbury MD, Heyliger SO. Preparation and characterization of lipophilic doxorubicin pro-drug micelles. $J$ Visual Exp. 2016;(114). doi: $10.3791 / 54338$

85. Jhaveri AM, Torchilin VP. Multifunctional polymeric micelles for delivery of drugs and siRNA. Front Pharmacol. 2014;5:77.

86. Wang Q, Jiang J, Chen W, Jiang H, Zhang Z, Sun X. Targeted delivery of low-dose dexamethasone using PCL-PEG micelles for effective treatment of rheumatoid arthritis. $J$ Control Release. 2016;230:64-72. doi:10.1016/j.jconrel.2016.03.035

87. Lammers $T$. Improving the efficacy of combined modality anticancer therapy using HPMA copolymer-based nanomedicine formulations. Adv Drug Deliv Rev. 2010;62(2):203-230. doi:10.1016/j.addr.2009.11.028

88. Feng Q, Tong R. Anticancer nanoparticulate polymer-drug conjugate. Bioeng Transl Med. 2016;1(3):277-296.

89. Wang $\mathrm{Y}, \mathrm{Wu} \mathrm{M}, \mathrm{Gu} \mathrm{L}$, et al. Effective improvement of the neuroprotective activity after spinal cord injury by synergistic effect of glucocorticoid with biodegradable amphipathic nanomicelles. Drug Deliv. 2017;24(1):391-401. doi:10.1080/ 10717544.2016.1256003

90. Kala H, Traue J, Moldenhauer H, Zessin G. [The use of spray drying in pharmacy (author's transl)]. Die Pharmazie. 1979;34 (12):779-784. German.

91. Ceschan NE, Bucala V, Ramirez-Rigo MV, Smyth HD. Impact of feed counterion addition and cyclone type on aerodynamic behavior of alginic-atenolol microparticles produced by spray drying. Eur J Pharm Biopharm. 2016;109:72-80. doi:10.1016/j.ejpb.2016.09.020

92. Harsha SN, Aldhubiab BE, Nair AB, et al. Nanoparticle formulation by Buchi B-90 nano spray dryer for oral mucoadhesion. Drug Des Devel Ther. 2015;9:273-282. doi:10.2147/DDDT.S66654

93. Sosnik A, Seremeta KP. Advantages and challenges of the spray-drying technology for the production of pure drug particles and drug-loaded polymeric carriers. Adv Colloid Interface Sci. 2015;223:40-54. doi:10.1016/j.cis.2015.05.003

94. Nguyen CT, Kim CR, Le TH, Koo KI, Hwang CH. Magnetically guided targeted delivery of erythropoietin using magnetic nanoparticles: proof of concept. Medicine. 2020;99(19):e19972. doi:10.1097/MD.0000000000019972

95. Strebhardt K, Ullrich A. Paul Ehrlich's magic bullet concept: 100 years of progress. Nat Rev Cancer. 2008;8(6):473-480. doi:10.1038/nrc2394

96. Tietze R, Lyer S, Dürr S, et al. Efficient drug-delivery using magnetic nanoparticles-biodistribution and therapeutic effects in tumour bearing rabbits. Nanomed Nanotechnol Biol Medi. 2013;9 (7):961-971. doi:10.1016/j.nano.2013.05.001

97. Andhari SS, Wavhale RD, Dhobale KD, et al. Self-propelling targeted magneto-nanobots for deep tumor penetration and pH-responsive intracellular drug delivery. Sci Rep. 2020;10 (1):4703. doi:10.1038/s41598-020-61586-y

98. Lueshen E, Venugopal I, Soni T, Alaraj A, Linninger A. Implantassisted intrathecal magnetic drug targeting to aid in therapeutic nanoparticle localization for potential treatment of central nervous system disorders. J Biomed Nanotechnol. 2015;11(2):253-261. doi:10.1166/jbn.2015.1907

99. Lueshen E, Venugopal I, Kanikunnel J, Soni T, Alaraj A, Linninger A. Intrathecal magnetic drug targeting using gold-coated magnetite nanoparticles in a human spine model. Nanomedicine. 2014;9(8):1155-1169. doi:10.2217/nnm.13.69

100. Hournkumnuard K, Natenapit M. Magnetic drug targeting by ferromagnetic microwires implanted within blood vessels. Med Phys. 2013;40(6Part1):062302. doi:10.1118/1.4805097

101. Wei HYJ, Luo C, Xu Z, Xu Z. Development of single-side magnet array for super paramagnetic nano-particle targeting. RES J Appl Sci Eng Technol. 2014;7(15):3022-3029. doi:10.19026/rjaset.7.637
102. Nacev A, Weinberg IN, Stepanov PY, et al. Dynamic inversion enables external magnets to concentrate ferromagnetic rods to a central target. Nano Lett. 2015;15(1):359-364. doi:10.1021/ $\mathrm{n} 1503654 \mathrm{t}$

103. Shapiro B, Kulkarni S, Nacev A, Muro S, Stepanov PY, Weinberg IN. Open challenges in magnetic drug targeting. Wiley Interdiscip Rev Nanomed Nanobiotechnol. 2015;7(3):446-457. doi:10.1002/wnan.1311

104. Do TD, Ul Amin F, Noh Y, Kim MO, Yoon J. Guidance of magnetic nanocontainers for treating Alzheimer's disease using an electromagnetic, targeted drug-delivery actuator. $J$ Biomed Nanotechnol. 2016;12(3):569-574. doi:10.1166/jbn.2016.2193

105. Baumann R, Glöckl G, Nagel S, Weitschies W. Preparation and characterization of magnetizable aerosols. Eur J Pharm Sci. 2012;45(5):693-697. doi:10.1016/j.ejps.2012.01.009

106. Voronin DV, Sindeeva OA, Kurochkin MA, et al. In vitro and in vivo visualization and trapping of fluorescent magnetic microcapsules in a bloodstream. ACS Appl Mater Interfaces. 2017;9 (8):6885-6893. doi:10.1021/acsami.6b15811

107. Yu J, Jin D, Chan KF, Wang Q, Yuan K, Zhang L. Active generation and magnetic actuation of microrobotic swarms in bio-fluids. Nat Commun. 2019;10(1):5631. doi:10.1038/s41467019-13576-6

108. Xu HL, Mao KL, Huang YP, et al. Glioma-targeted superparamagnetic iron oxide nanoparticles as drug-carrying vehicles for theranostic effects. Nanoscale. 2016;8(29):14222-14236. doi:10.1039/C6NR02448C

109. Uebe R, Schuler D. Magnetosome biogenesis in magnetotactic bacteria. Nat Rev Microbiol. 2016;14(10):621-637.

110. Marty JJ, Oppenheim RC, Speiser P. Nanoparticles - a new colloidal drug delivery system. Pharm Acta Helv. 1978;53 (1):17-23.

111. Pareek V, Bhargava A, Bhanot V, Gupta R, Jain N, Panwar J. Formation and characterization of protein corona around nanoparticles: a review. J Nanosci Nanotechnol. 2018;18 (10):6653-6670. doi:10.1166/jnn.2018.15766

112. Janko C, Dürr S, Munoz LE, et al. Magnetic drug targeting reduces the chemotherapeutic burden on circulating leukocytes. Int J Mol Sci. 2013;14(4):7341-7355. doi:10.3390/ijms14047341

113. Majidi S, Sehrig FZ, Farkhani SM, Goloujeh MS, Akbarzadeh A. Current methods for synthesis of magnetic nanoparticles. Artif Cells Nanomed Biotechnol. 2016;44(2):722-734. doi:10.3109/ 21691401.2014.982802

114. Mascolo MC, Pei Y, Ring TA. Room temperature co-precipitation synthesis of magnetite nanoparticles in a large $\mathrm{pH}$ window with different bases. Materials (Basel). 2013;6(12):5549-5567. doi:10.3390/ma6125549

115. Sela H, Cohen H, Elia P, Zach R, Karpas Z, Zeiri Y. Spontaneous penetration of gold nanoparticles through the blood brain barrier (BBB). J Nanobiotechnology. 2015;13:71. doi:10.1186/s12951015-0133-1

116. Kong SD, Lee J, Ramachandran S, et al. Magnetic targeting of nanoparticles across the intact blood-brain barrier. $J$ Control Release. 2012;164(1):49-57.

117. Atkinson IC, Renteria L, Burd H, Pliskin NH, Thulborn KR. Safety of human MRI at static fields above the FDA $8 \mathrm{~T}$ guideline: sodium imaging at $9.4 \mathrm{~T}$ does not affect vital signs or cognitive ability. JMRI. 2007;26(5):1222-1227. doi:10.1002/jmri.21150

118. La Z Guidance for magnetic resonance diagnostic devices - criteria for significant risk investigations. U.S.: CDRH, FDA, and DHHS. I; 2003. http://www.fda.gov/cdrh/ode/guidance/793.html. Accessed August 24, 2007.

119. Khan FA, Almohazey D, Alomari M, Almofty SA. Impact of nanoparticles on neuron biology: current research trends. Int $J$ Nanomedicine. 2018;13:2767-2776. doi:10.2147/IJN. S165675 
120. Tietze $\mathrm{R}$, Zaloga J, Unterweger $\mathrm{H}$, et al. Magnetic nanoparticle-based drug delivery for cancer therapy. Biochem Biophys Res Commun. 2015;468(3):463-470. doi:10.1016/j. bbrc.2015.08.022

121. Taherkhani S, Mohammadi M, Daoud J, Martel S, Tabrizian M. Covalent binding of nanoliposomes to the surface of magnetotactic bacteria for the synthesis of self-propelled therapeutic agents. ACS Nano. 2014;8(5):5049-5060. doi:10.1021/nn5011304

122. Mashjoor S, Yousefzadi M, Zolgharnain H, Kamrani E, Alishahi M. Organic and inorganic nano-Fe3O4: alga Ulva flexuosa-based synthesis, antimicrobial effects and acute toxicity to briny water rotifer Brachionus rotundiformis. Environ Pollut. 2018;237:50-64. doi:10.1016/j.envpol.2018.02.036

123. Erickson HP. Size and shape of protein molecules at the nanometer level determined by sedimentation, gel filtration, and electron microscopy. Biol Proced Online. 2009;11:32-51.

124. Beh CY, How CW, Foo JB, Foong JN, Selvarajah GT, Rasedee A. Development of erythropoietin receptor-targeted drug delivery system against breast cancer using tamoxifen-loaded nanostructured lipid carriers. Drug Des Devel Ther. 2017;11:771-782. doi:10.2147/DDDT.S123939

125. Bordbar AK, Rastegari AA, Amiri R, Ranjbakhsh E, Abbasi M, Khosropour AR. Characterization of modified magnetite nanoparticles for albumin immobilization. Biotechnol Res Int. 2014;2014:6. doi:10.1155/2014/705068

126. Saranya T, Parasuraman K, Anbarasu M, Balamurugan K. XRD, FT-IR and SEM study of magnetite (Fe3O4) nanoparticles prepared by hydrothermal method. Nano Vision. 2015;5 (4-6):149-154.

127. Mahdavi M, Ahmad MB, Haron MJ, et al. Synthesis, surface modification and characterisation of biocompatible magnetic iron oxide nanoparticles for biomedical applications. Molecules. 2013;18(7):7533-7548. doi:10.3390/molecules 18077533

128. Cohan RA, Madadkar-Sobhani A, Khanahmad H, et al. Design, modeling, expression, and chemoselective PEGylation of a new nanosize cysteine analog of erythropoietin. Int J Nanomedicine. 2011;6:1217-1227.

129. Yen FS, Chen WC, Yang JM, Hong CT. Crystallite size variations of nanosized $\mathrm{Fe} 2 \mathrm{O} 3$ powders during $\gamma$ - to $\alpha$-phase transformation. Nano Lett. 2002;2(3):245-252. doi:10.1021/n1010089m

130. Guadarrama-Acevedo MC, Mendoza-Flores RA, Del PradoAudelo ML, et al. Development and evaluation of alginate membranes with curcumin-loaded nanoparticles for potential wound-healing applications. Pharmaceutics. 2019;11(8):389. doi:10.3390/pharmaceutics11080389

131. Pouponneau P, Soulez G, Beaudoin G, Leroux JC, Martel S. MR imaging of therapeutic magnetic microcarriers guided by magnetic resonance navigation for targeted liver chemoembolization. Cardiovasc Intervent Radiol. 2014;37(3):784-790. doi:10.1007/ s00270-013-0770-4

132. Novoselova MV, German SV, Sindeeva OA, et al. Submicronsized nanocomposite magnetic-sensitive carriers: controllable organ distribution and biological effects. Polymers. 2019;11 (6):1082. doi:10.3390/polym11061082

133. Edman P, Ekman B, Sjoholm I. Immobilization of proteins in microspheres of biodegradable polyacryldextran. J Pharm Sci. 1980;69(7):838-842. doi:10.1002/jps.2600690725

134. Narhi LO, Arakawa T, Aoki KH, et al. The effect of carbohydrate on the structure and stability of erythropoietin. J Biol Chem. 1991;266(34):23022-23026.

135. Cedervall T, Lynch I, Lindman S, et al. Understanding the nanoparticle-protein corona using methods to quantify exchange rates and affinities of proteins for nanoparticles. Proc Natl Acad Sci $U$ S A. 2007;104(7):2050-2055. doi:10.1073/pnas.06 08582104
136. Owens DE, Peppas NA. Opsonization, biodistribution, and pharmacokinetics of polymeric nanoparticles. Int J Pharm. 2006;307 (1):93-102. doi:10.1016/j.ijpharm.2005.10.010

137. Pinkernelle J, Calatayud P, Goya GF, Fansa H, Keilhoff G. Magnetic nanoparticles in primary neural cell cultures are mainly taken up by microglia. BMC Neurosci. 2012;13:32. doi:10.1186/ 1471-2202-13-32

138. Vonarbourg A, Passirani C, Saulnier P, Benoit JP. Parameters influencing the stealthiness of colloidal drug delivery systems. Biomaterials. 2006;27(24):4356-4373.

139. Li L, Okada H, Takemura G, et al. Sustained release of erythropoietin using biodegradable gelatin hydrogel microspheres persistently improves lower leg ischemia. J Am Coll Cardiol. 2009;53 (25):2378-2388. doi:10.1016/j.jacc.2009.02.056

140. Jelkmann W. Molecular biology of erythropoietin. Internal Med. 2004;43(8):649-659. doi:10.2169/internalmedicine.43.649

141. Bogdanov SV. The origin of the piezoelectric effect in pyroelectric crystals. IEEE Trans Ultrason Ferroelectr Freq Control. 2002;49(11):1469-1473. doi:10.1109/TUFFC.2002.1049727

142. Ma SW, Fan YJ, Li HY, Su L, Wang ZL, Zhu G. Flexible porous polydimethylsiloxane/lead zirconate titanate-based nanogenerator enabled by the dual effect of ferroelectricity and piezoelectricity. ACS Appl Mater Interfaces. 2018;10(39):33105-33111. doi:10.1021/acsami.8b06696

143. Chen X, Parida K, Wang J, et al. A stretchable and transparent nanocomposite nanogenerator for self-powered physiological monitoring. ACS Appl Mater Interfaces. 2017;9 (48):42200-42209. doi:10.1021/acsami.7b13767

144. Panja S, Maji S, Maiti TK, Chattopadhyay S. A smart magnetically active nanovehicle for on-demand targeted drug delivery: where van der Waals force balances the magnetic interaction. ACS Appl Mater Interfaces. 2015;7(43):24229-24241. doi:10.1021/ acsami.5b07706

145. Saito T, Kuramae R, Wohlert J, Berglund LA, Isogai A. An ultrastrong nanofibrillar biomaterial: the strength of single cellulose nanofibrils revealed via sonication-induced fragmentation. Biomacromolecules. 2013;14(1):248-253. doi:10.1021/ bm $301674 \mathrm{e}$

146. Soma CE, Dubernet C, Barratt G, Benita S, Couvreur P. Investigation of the role of macrophages on the cytotoxicity of doxorubicin and doxorubicin-loaded nanoparticles on M5076 cells in vitro. $J$ Control Release. 2000;68(2):283-289. doi:10.1016/S0168-3659(00)00269-8

147. Walkey CD, Olsen JB, Guo H, Emili A, Chan WC. Nanoparticle size and surface chemistry determine serum protein adsorption and macrophage uptake. $J$ Am Chem Soc. 2012;134 (4):2139-2147. doi:10.1021/ja2084338

148. Townsley MI. Structure and composition of pulmonary arteries, capillaries, and veins. Compr Physiol. 2012;2(1):675-709.

149. Hafeli UO, Saatchi K, Elischer P, et al. Lung perfusion imaging with monosized biodegradable microspheres. Biomacromolecules. 2010;11(3):561-567. doi:10.1021/bm9010722

150. Odrobińska J, Gumieniczek-Chłopek E, Szuwarzyński M, et al. Magnetically navigated core-shell polymer capsules as nanoreactors loadable at the oil/water interface. ACS Appl Mater Interfaces. 2019;11(11):10905-10913. doi:10.1021/acsami.8b 22690

151. Pedram MZ, Shamloo A, Alasty A, Ghafar-Zadeh E. Optimal magnetic field for crossing super-para-magnetic nanoparticles through the brain blood barrier: a computational approach. Biosensors. 2016;6(2):25. doi:10.3390/bios6020025

152. Hainfeld JF, Smilowitz HM, O’Connor MJ, Dilmanian FA, Slatkin DN. Gold nanoparticle imaging and radiotherapy of brain tumors in mice. Nanomedicine. 2013;8(10):1601-1609. doi:10.2217/nnm.12.165 
153. Shilo M, Motiei M, Hana P, Popovtzer R. Transport of nanoparticles through the blood-brain barrier for imaging and therapeutic applications. Nanoscale. 2014;6(4):2146-2152. doi:10.1039/ C3NR04878K

154. Etame AB, Diaz RJ, O'Reilly MA, et al. Enhanced delivery of gold nanoparticles with therapeutic potential into the brain using MRI-guided focused ultrasound. Nanomed Nanotechnol Biol Medi. 2012;8(7):1133-1142.

155. Dhanushkodi A, Akano EO, Roguski EE, et al. A single intramuscular injection of rAAV-mediated mutant erythropoietin protects against MPTP-induced parkinsonism. Genes Brain Behav. 2013;12(2):224-233. doi:10.1111/gbb.12001

156. Dmytriyeva O, Pankratova S, Korshunova I, Walmod PS. Epobis is a nonerythropoietic and neuroprotective agonist of the erythropoietin receptor with anti-inflammatory and memory enhancing effects. Mediators Inflamm. 2016;2016:1346390. doi:10.1155/ 2016/1346390

157. Xicoy H, Wieringa B, Martens GJ. The SH-SY5Y cell line in Parkinson's disease research: a systematic review. Mol Neurodegener. 2017;12(1):10. doi:10.1186/s13024-017-0149-0

158. Yoo JY, Won YJ, Lee JH, et al. Neuroprotective effects of erythropoietin posttreatment against kainate-induced excitotoxicity in mixed spinal cultures. J Neurosci Res. 2009;87(1):150-163.

159. Seaton A, Tran L, Aitken R, Donaldson K. Nanoparticles, human health hazard and regulation. J Royal Soc Interface. 2010;7(Suppl 1):S119-129. doi:10.1098/rsif.2009.0252.focus

160. Moreno-Horn M, Gebel T. Granular biodurable nanomaterials: no convincing evidence for systemic toxicity. Crit Rev Toxicol. 2014;44(10):849-875. doi:10.3109/10408444.2014.938802

161. Huang YW, Cambre M, Lee HJ. The toxicity of nanoparticles depends on multiple molecular and physicochemical mechanisms. Int J Mol Sci. 2017;18(12):2702. doi:10.3390/ijms18122702
162. Sharma M. Understanding the mechanism of toxicity of carbon nanoparticles in humans in the new millennium: a systemic review. Indian J Occup Environ Med. 2010;14(1):3-5.

163. Chakraborty $\mathrm{C}$, Hsu CH, Wen ZH, Lin CS, Agoramoorthy G. Zebrafish: a complete animal model for in vivo drug discovery and development. Curr Drug Metab. 2009;10(2):116-124. doi:10.2174/138920009787522197

164. Beliaeva NF, Kashirtseva VN, Medvedeva NV, Khudoklinova I, Ipatova OM, Archakov AI. [Zebrafish as a model organism for biomedical studies]. Biomed Khim. 2010;56(1):120-131.

165. Easter, Jr. SS, Nicola GN. The development of vision in the zebrafish (Danio rerio). Dev Biol. 1996;180(2):646-663. doi:10.1006/dbio.1996.0335

166. Fishman MC. Zebrafish genetics: the enigma of arrival. Proc Natl Acad Sci U S A. 1999;96(19):10554-10556. doi:10.1073/ pnas.96.19.10554

167. Sabourin VAA, Ayande A. Commercial opportunities and market demand for nanotechnologies in agribusiness sector. J Technol Manag Innov. 2015;10:40-51. doi:10.4067/S0718-27242015 000100004

168. Vance ME, Kuiken T, Vejerano EP, et al. Nanotechnology in the real world: redeveloping the nanomaterial consumer products inventory. Beilstein $J$ Nanotechnol. 2015;6:1769-1780. doi:10.3762/bjnano.6.181

169. Freeman MWA, Watson JHL, Watson JHL. Magnetism in medicine. J Appl Phys. 1960;31:S404-S405. doi:10.1063/ 1.1984765

170. Daldrup-Link HE. Ten things you might not know about iron oxide nanoparticles. Radiology. 2017;284(3):616-629. doi:10.1148/radiol.2017162759
International Journal of Nanomedicine

\section{Publish your work in this journal}

The International Journal of Nanomedicine is an international, peerreviewed journal focusing on the application of nanotechnology in diagnostics, therapeutics, and drug delivery systems throughout the biomedical field. This journal is indexed on PubMed Central, MedLine, CAS, SciSearch ${ }^{\circledR}$, Current Contents ${ }^{\circledR} /$ Clinical Medicine,
Journal Citation Reports/Science Edition, EMBase, Scopus and the Elsevier Bibliographic databases. The manuscript management system is completely online and includes a very quick and fair peer-review system, which is all easy to use. Visit http://www.dovepress.com/ testimonials.php to read real quotes from published authors. 